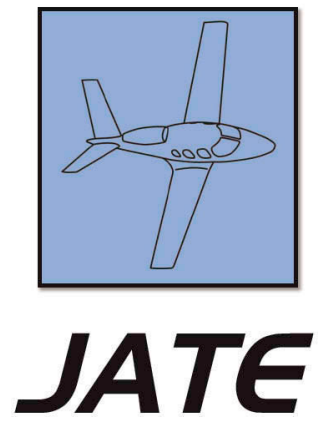

Journal of Aviation Technology and Engineering 5:2 (2016) 27-50

\title{
Estimation of Performance Airspeeds for High-Bypass Turbofans Equipped Transport-Category Airplanes
}

\author{
Nihad E. Daidzic \\ AAR Aerospace Consulting, LLC
}

\begin{abstract}
Conventional Mach-independent subsonic drag polar does not replicate the real airplane drag characteristics exactly and especially not in the drag-divergence region due to shock-induced transonic wave drag. High-bypass turbofan thrust is a complicated function of many parameters that eludes accurate predictions for the entire operating envelope and must be experimentally verified. Fuel laws are also complicated functions of many parameters which make optimization and economic analysis difficult and uncertain in the conceptual design phase. Nevertheless, mathematical models and predictions have its important place in aircraft development, design, and optimization. In this work, airspeed-dependent turbofan thrust and the new fuel-law model were used in combination with an airplane polynomial drag model to estimate important performance speeds. Except for the airframe-only dependent control airspeeds, all performance speeds are airframepowerplant dependent. In all analytical considerations one ends up with polynomials of the $4^{\text {th }}$ order that have no closed-form solutions. A real positive-root seeking numerical procedure based on the family of Newton-Raphson methods was used to extract performance airspeeds for variable in-flight weights and altitudes in the ISA troposphere. Extensive testing of the accuracy and convergence of the Newton-Raphson nonlinear equation solvers was conducted before performance speed calculations. A fictitious long-range wide-body transport-category airplane was modeled in combination with a pair of high-bypass and ultra-high bypass ratio flat-rated turbofans. Procedure employed here can be easily extended to cases when fitted, measured drag and thrust data is given in arbitrary polynomial forms. Sensitivity analysis is performed on minimum-drag airspeed and maximum aerodynamic efficiency. Transonic wave drag considerations are introduced.
\end{abstract}

Keywords: Transport-category airplane, High-bypass turbofan, Thrust, Fuel law and TSFC, Drag polar, Performance airspeeds, Newton-Raphson nonlinear equation solvers, Transonic wave drag.

\footnotetext{
About the Authors

Dr. Nihad E. Daidzic is president of AAR Aerospace Consulting, LLC. He is also a full professor of aviation, adjunct professor of mechanical engineering, and research graduate faculty at Minnesota State University. He has a PhD in fluid mechanics and $\mathrm{ScD}$ in mechanical engineering. He was formerly a staff scientist at the National Center for Microgravity Research and the National Center for Space Exploration and Research at NASA Glenn Research Center in Cleveland, $\mathrm{OH}$. He has also held various faculty appointments at Vanderbilt University, University of Kansas, and Kent State University. His current research interest is in theoretical, experimental, and computational fluid dynamics; micro- and nano-fluidics; aircraft stability, control, and performance; and mechanics of flight, piloting techniques, and aerospace propulsion. Dr. Daidzic is ATP and "Gold Seal" CFII/MEI/CFIG certified with flight experience in airplanes, helicopters, and gliders.
} 


\section{Introduction}

In order to optimize airplane operation and predict its performance in the conceptual design phase, early estimates of control and performance airspeeds are important. Much of the aircraft field and cruise performance capabilities depend on the set of control and performance airspeeds, such as, rotation, takeoff safety, climb, maximum- and long-range cruising, and reference landing speeds. Pilots essentially fly airplanes by reference to set of optimum airspeeds. Best flight practices depend much on the ability of pilots to maintain set airspeeds optimized for each phase of flight.

Completed aircraft prototypes must undergo experimental verification before being certified. Aircraft manufacturers obtain such specific information by performing numerous repetitive, tedious, and expensive flight tests (Daidzic, 2013; FAA 2011). Flight testing campaigns do not normally contribute much to understanding of flight physics, but are a required step toward particular airplane certification (EASA, 2007; FAA, 2013; JAA 2007). Indeed, all limitations, control, and gross performance figures entering approved airplane operational/flight manuals (Airplane Flight Manual and Flight Crew Operations Manual) must be based on measured data (Daidzic, 2013; Eshelby 2000). Airframe and engine characteristics cannot be presently modeled and simulated with fidelity, reliability, and accuracy required to substitute measured test data for certification purposes (Eshelby, 2000).

Although validation of analytical and computational calculations and wind-tunnel scale experiments must be verified during flight tests, nevertheless, the analytical methods provide deeper understanding of the fundamental flight physics and enable local and global optimizations. This is a crucial step in predicting aircraft performance and economy of operation, and in designing best piloting technique practices (Daidzic, 2008).

Characteristics of modern HBPR (high) and UHBPR (ultra-high) BPR (bypass ratio) turbofans are profoundly speed dependent (Anderson, 1999; Hale, 1984; Jaw \& Mattingly, 2009; Mair \& Birdsall, 1992; Mattingly, 2005; Phillips, 2004). Some functional relationships do exist, but to have faithful analytical descriptions of thrust available for the entire flight envelope of modern engines is almost impossible. Although there are quite sophisticated and complex turbofan simulation models (e.g., Jaw \& Mattingly, 2009; Walsh \& Fletcher, 1998), they are inappropriate for conceptual-design aircraft performance calculations as performed here.

Some important performance airspeeds treated, for both All Engines Operating (AEO) and One Engine Inoperative (OEI) conditions and as a function of in-flight weight, are the minimum drag $V_{M D}$, steepest climb $V_{X}$, maximumendurance $V_{E}$, minimum-power $V_{M P}$, maximum rate of climb $V_{Y}$, the maximum-cruise range airspeed $V_{M R C}$, and the minimum and the maximum propulsion-limited level flight airspeeds $V_{M I N}$ and $V_{M A X}$.

\section{Literature Review}

Many existing introductory and expert books dealing with the airplane performance in general, and transport-category (T-category) airplanes certified under FAR/EASA certification standard (CS) 25 in particular, use relatively simple functional relationships between, most often, speed-independent trust and conventional Mach-independent subsonic drag polar to obtain performance speeds (Anderson, 1999; Asselin, 1997, Eshelby, 2000; Filippone, 2006, 2012; Hale, 1984; Mair \& Birdsall, 1992; McCormick, 1995; Nicolai and Carichner, 2010; Ojha, 1995; Raymer, 1999; Roskam \& Lan, 1997; Saarlas, 2007; Shevell, 1989; Torenbeek \& Wittenberg, 2009; Vinh, 1993). This is also understandable as the resulting equations are nonlinear and no closed-form solutions exist in most cases.

Estimation and optimization of performance airspeeds for various phases of flight is an essential part of aircraft design, testing, and certification, but also in economy and safety of flight operations. Shevell (1989) gives a very nice introduction on compressibility effects and drag on airfoils and wings. The author also provides a semi-empirical relationship for the estimation of the drag-divergence Mach $\left(M_{D D}\right)$ number based on the critical Mach $\left(M_{C R}\right)$ number for swept wings. Menon (1989) has studied aircraft cruise from the aspect of trajectory optimization and comparing his theory with the point-mass and energy models. The author has shown that oscillatory cruise trajectories exist if the Hessian of a characteristic function is positive definite. Miller (1993) also studied optimal cruise performance and the determination of optimal cruise speeds. Miller has concluded that the optimal cruise Mach $(M)$ number occurs in the drag-rise region, i.e., between the $M_{C R}$ and $M_{D D}$. Wave drag becomes noticeable once the $M_{C R}$ is exceeded, but truly significant once the $M_{D D}$ is surpassed. Mason (1995) uses the potential flow model for aerodynamic design at transonic speeds. The author points out the principal shortcomings of potential flow models in terms that can be easily understood by aerodynamicists. Malone and Mason (1995) present an approach to multidisciplinary aircraft design optimization that combines the global sensitivity equation method, parametric optimization, and analytic technology models. An expression for wave drag and $M_{D D}$ is given for swept-wing aircraft-an extension of the classical Korn equation. Torenbeek (1997) provides exhaustive consideration, unified analytical treatment, and optimization techniques for the cruise performance of subsonic transport aircraft. A simple alternative to the celebrated Bréguet range equation is presented that applies to several practical cruise techniques. A practical non-iterative procedure for computing mission fuel and reserve fuel loads in the preliminary design stage was proposed. Mason (2002) provides an extended summary of transonic aerodynamics of airfoils and (finite) wings. Historical development and facts were included, which show the tortuous path in 
understanding and solving transonic flow problems. Isikveren (2002) presents a treatment of identification of optimal flight techniques for transport aircraft with respect to direct operating cost and profit, or return on investment is derived for given sector mission criteria. The author proposes a new cruise technique that could replace the common industry-standard long-range cruise (LRC) at 99\% specific air range (SAR). All operating considerations are based on the cost index (CI), which is the most suitable method in defining the new economical LRC (ELRC). Fujino and Kawamura (2003) present an experimental and theoretical study of wave-drag reduction and increase in $M_{D D}$ in the case of over-the-wing nacelle configuration. Such nacelle configuration reduces transonic cruise drag without altering the original geometry of the natural-laminarflow wing.

Cavalcanti and Papini (2004) discussed construction of aerodynamic databases required for design and optimization of then new Embraer 170 jet. The validation of the dynamic aerodynamic model designed in Simulink/MATLAB was confirmed in actual flight tests. Raymer (2004) derived an approximate method to derive loiter (endurance) time from the Bréguet range equation. Cavcar and Cavcar (2004) deliver approximate cruise range solutions for the constantaltitude and constant-high-subsonic cruise speeds of a transport category aircraft with cambered wing designs. The authors also used Mach-dependent specific fuel consumption (SFC), which is different from the one introduced here. The effect of Mach number on the drag polar was used when deriving approximate solutions. Wave drag was considered when estimating optimum $(M \cdot L / D)$ factor. It was found that compressibility effects necessitate use of higher-order polynomial drag polar.

Cavcar and Cavcar (2005) discussed the optimum range and endurance of a piston-propeller aircraft with cambered wing and derived analytical expressions without having to resort to substitution of the optimum airspeeds. Ghenaiet (2007) discusses determination of the minimum thrust requirements for passenger aircraft utilizing mathematically complex sequential quadratic programming and other optimal solutions methods to solve constrained optimization problems. Euston, Coote, Mahony, Kim, and Hamel (2008) used explicit complementary filter (ECF) for attitude estimation that can be used for Unmanned Aerial Vehicle (UAV) attitude control, but also during flight testing of transport-category airplanes. ECF with Inertial Measurement Unit (IMU) and dynamic pressure measurements achieved attitude filtering performance of the same quality as a full extended Kalman filter (EKF) that exploited full GPS/IRS/ INS data. Thus ECF shows significant potential as a simple robust attitude filter for small UAV vehicles.

Rivas and Valenzuela (2009) analyzed maximum range cruise at constant altitude as a singular optimal control problem for an aircraft model with a general compressible drag polar. Compressibility effects must be taken into account when seeking optimum cruise solutions in terms of speed and range. The influence of flight altitude on optimal trajectories was shown to be important as well. The authors left open the solution of minimizing direct operating cost. Results presented were for a B767-300ER model, a popular long-range twin jet.

Lie and Gebre-Egziabher (2013) presented a method for estimating airspeed, angle-of-attack (AOA), and sideslip angle without using conventional Pitot-static air data. The method relies on GPS data, IMU data, and a low-fidelity aircraft dynamics model, which are then fused together using two cascade EKFs. This method can also be used in flight testing of FAR 25 airplanes. It was demonstrated in the case of a C172 GA light plane with the estimated air data being in good agreement with the conventionally measured air data. Torenbeek (2013) offers an advanced expert book on aircraft conceptual design, analysis, and optimization of subsonic civil aircraft. Optimum cruise Mach number is deep in the drag rise region and closer to $M_{D D}$ than to $M_{C R}$.

Recently, Daidzic (2014b) discussed the global range (GR) of subsonic and supersonic aircraft and the required aerodynamic and propulsion developments needed to meet it. Nevertheless, to the best of our knowledge no archived public-domain reference in which a systematic approach and methods for calculations of performance airspeeds was found. Most of the discussion and problem treatment in every expert book on aircraft performance almost exclusively focuses on speed-independent thrust equation. In such cases only quadratic equations containing airframe drag data are treated and are easily solved. Only in Phillips (2004) did we find a method of solution for the nonlinear speed estimation problem when considering the maximum airspeed of propeller-driven airplane. In particular, Phillips used the Newton-Raphson method, the same method that will be employed here. Saarlas (2007) and Vinh (1993) entertained several nonlinear problems in performance airspeed estimation, but never provided solutions or methods. We do not, however, exclude the possibility that similar method(s) were and are used by various airplane manufacturers in the airplane preliminary design and development phases.

Therefore, a consistent and systematic definition, identification, and numerical calculation for estimation of performance speeds is provided here. This can be easily extended to cases where drag and thrust data is extracted from measured and statistically smoothed data and transformed into arbitrary-order polynomial form by least-square approximations/fitting analysis.

The main goal of this article is to use a realistic integral turbofan model(s) and together with the airframe subsonic drag and power required relationships provide definitions of all critical performance speeds. As it will be seen later, most of the resulting analytical expressions do not have explicit analytic closed-form solutions. All functional 
expressions discussed here end up with $4^{\text {th }}$ order polynomials, which in most cases must be solved numerically. In that respect we used several real (with multiplicity) and complex-conjugate root-finding methods (nonlinear equations solvers). Subsequent analysis of turbofan characteristics also revealed strong influence of BPR on performance airspeeds. A new semi-empirical fuel law is proposed, which is valid in the entire operational envelope of any conventional turbofan or turbojet engine.

\section{Mathematical Model}

The mathematical model used here is based on a standard non-orbiting flat-Earth airplane flight model in vertical plane (Vinh, 1993). Angles of climb are small, and all trigonometric functions are linearly approximated. Acceleration in constant-Equivalent AirSpeed (EAS)/Calibrated AirSpeed (CAS) climb is neglected. A new, efficient, and fast algorithm for International Standard Atmosphere (ISA) calculations (Daidzic, 2015) is used for all performance estimates. All altitudes are orthometric (reference Geoid) or Mean Sea Level (MSL). Partial wing unloading due to the vertical thrust component and the corresponding reduced power-on stall speeds was neglected. Thrust action line was assumed to be colinear with the airplane's longitudinal axis. The location of the airplane CG and its effect on the stalling speed was neglected.

Turbofan models used are based on the semi-empirical considerations of the momentum drag and ram compression (Daidzic, 2012). The effect of altitude is included in both models for thrust and TSFC (Thrust Specific Fuel Consumption). Performance airspeeds that are functions of speed-dependent thrust cannot be solved in an explicit (closed) form. The advantage of the presented mathematical model is that it results in an implicit functional relationship between the critical performance airspeeds and the basic airplane, engine, and environmental conditions. The larger problem of aircraft design optimization and engine-airframe integration and optimization is not considered. Many good books exist that touch on this subject (e.g., Torenbeek, 2013).

Again, the main goal was to present a unified approach in determining the critical airplane airspeeds in the design phase based on the known total drag and thrust data in speed-dependent polynomial form. However, once the flight testing is complete and the drag and thrust data polynomials are known to high accuracy, the final critical airspeeds can be accurately calculated based on the nonlinear solvers presented here.

\section{Airplane Drag and Power Required}

Determination of airplane drag is usually the most difficult task when estimating airplane performance. For a general high-subsonic speed T-category airplane, the aerodynamic drag, for the most part, consists of zero lift drag, drag due to lift, and, in a much smaller amount, wave drag. The wave drag originates in transonic flow over the wing and fuselage. The very definition of the transonic flow (Ashley \& Landahl, 1985; Filippone, 2012; Liepmann \& Roshko, 2001) means the coexistence of pockets of subsonic and supersonic flow. The integral aerodynamic behavior of an entire airplane is conveniently given through macroscopic coefficients of lift and drag for specified profile/wing geometry as:

$$
C_{D}=f(\alpha, \beta, R e, M) \quad C_{L}=g(\alpha, \beta, R e, M)
$$

Reynolds number $(\mathrm{Re})$ dependence becomes significant only at extremely high altitudes and is neglected from further consideration. It is also assumed that an airplane is in trim flying at zero sideslip $\beta$, thus minimizing drag. All that is left is the dependence on the AOA or $\alpha$ and the Mach number. Complex functional relationships from Equation (1), reduces to $C_{D}=C_{D}\left(C_{L}, M\right)$. Small drag changes around the equilibrium point at relatively high Mach numbers (significant compressibility effects) and become:

$$
\Delta C_{D}=\left(\frac{\partial C_{D}}{\partial C_{L}}\right)_{M} \Delta C_{L}+\left(\frac{\partial C_{D}}{\partial M}\right)_{C_{L}} \Delta M
$$

A general drag equation consists of the section (airfoil, infinite wing, or 2D) drag and the finite-wing (3D) drag. Essentially, drag comes in the form of skin friction and form (pressure) drag, which is for 2D airfoil-termed profile drag. The transonic wave drag associated with the local supersonic flow terminating in normal (stronger) or oblique (weaker) shock waves is essentially a pressure drag. Supersonic wave drag on an infinite Aspect Ratio (AR) flat plate or thin airfoil has analytical solution, $C_{D w} \propto C_{l}^{2} \sqrt{M_{\infty}^{2}-1}$ (Anderson, 1999; Ashley, 1992). Thus wave drag due to lift is proportional to finite-wing $C_{L}^{2}$ and the coefficient is a function of the Mach number. Total drag for generic cambered transonic airfoil can be also represented as a sum of zero-lift drag (including parasitic wave drag component) and drag due to lift (viscous drag due to lift and inviscid vortex or induced drag plus the wave drag due to lift):

$$
\begin{aligned}
C_{D}= & \overbrace{C_{D 0}(M)+K_{1}(M) \cdot C_{L}+K_{2}(M) \cdot C_{L}^{2}}^{\text {section drag including parasitic wave-drag }} \\
& +\overbrace{K_{3}(M) \cdot C_{L}^{2}}^{\text {vortex drag }}+\overbrace{K_{4}(M) \cdot C_{L}^{2}}^{\text {wave-drag due-to-lift }}
\end{aligned}
$$

Below critical Mach $\left(M_{C R}\right)$ there are no local shocks anywhere on the wing, so there can be no wave drag either, although increasing Mach number is affecting pressure distribution and thus slightly viscous drag even below $M_{C R}$ (Mair and Birdsall, 1992). The modern supercritical airfoils delay the drag rise (divergence) or $M_{D D}$. This enables higher subsonic cruising airspeeds without incurring significant wave-drag penalty, but also transonic stability 
and control problems. According to Anderson (1999), Bertin \& Cummings (2009), and Thomas (1985), it is assumed for T-category airplanes flown below $M_{D D}$ that the transonic wave drag contributes about $5 \%$ of the total aircraft drag. On the other hand, the supersonic transport, such as Concorde at $M=2$, has more than two-thirds of the total drag in the form of the pressure wave drag (Anderson, 1999). Compressibility affects the coefficient-of-lift $\left(C_{L}\right)$, which is described simply by the asymptotic PrandtlGlauert rule (correction formula), or similar more advanced correction (Anderson, 1999; Ashley, 1992; Bertin \& Cummings 2009). There is also a small rise in zero-lift parasitic $C_{D O}$, not associated with the wave drag, from about Mach 0.6 or 0.7 upward until $M_{D D}$ the drag rise becomes significant (Ashley, 1992; Mair \& Birdsall, 1992; Vinh, 1993). The onset of significant wave drag rise due to strong normal shocks inducing localized boundary layer separation is typically based on the criterion that $\left(\partial C_{D} / \partial M\right)=0.1$ at the Mach drag-divergence number $M_{D D}$ (Cavcar \& Cavcar, 2004; Filippone, 2012; Mason, 2002; Raymer, 1999; Torenbeek, 1997). Sometimes another criterion is used for the $M_{D D}$ definition, and that is a Mach number at which compressibility wave drag increased by 0.002 (Cavcar \& Cavcar, 2004). While some wave drag exists between $M_{C R}$ and $M_{D D}$, it will be for the most part neglected in this study, and $M_{D D}$ will be taken as the maximum operating airspeed even when the powerplants are capable of accelerating an aircraft to higher M-speeds.

The entire issue of transonic flow is extremely complicated (Ashley and Landahl, 1985; Ashley, 1992), and experimental verification is the only fully reliable method to estimate its effect on the total drag. Recently some progress has been achieved by Jakirlić, Eisfeld, JesterZuerker, and Kroll (2007) utilizing CFD of supercritical airfoils (transonic RAE 2822 profiles) using the near-wall RANS (Reynolds-averaged Navier-Stokes) transonic flow turbulence model. Such complex CFD approach is cumbersome to implement in conceptual designs and the first drag estimates phase. However, according to Cavcar and Cavcar (2004), Malone and Mason (1995), Mason (2002), and Filippone (2012), the $M_{D D}$ as a function of lift coefficient and for given wing/airfoil geometry can be reasonably well estimated with:

$$
M_{D D}\left(C_{L}\right)=\frac{M_{D D 0}}{\cos \psi}-\frac{(t / c)_{\max }}{\cos ^{2} \psi}-\frac{b \cdot C_{L}}{\cos ^{3} \psi}
$$

This is the extended semi-empirical "Korn equation" (Malone \& Mason, 1995; Mason, 2002). Modern supercritical wing has zero-lift $M_{D D O}$ (also referred to as an "airfoil technology factor") in the range of 0.87 to 0.955 (Filippone, 2012; Mason, 2002), the maximum relative thickness around 0.1-0.15, and the leading-edge (LE) sweep angle of $35^{\circ}$ to $38^{\circ}$. For typical cruising airspeeds and altitudes, the $C_{L}$ is normally between 0.4 and 0.5 .
Using a value of 0.4 , the maximum relative thickness of $0.12, M_{D D O}$ of 0.92 , sweep angle of $35^{\circ}$, and $b=0.14$ from accepted range $(0.1-0.14)$ of values for supercritical wing sections (Filippone, 2012), the estimated drag-divergence Mach becomes 0.872 . For such airplane $M_{M O}$ could be 0.86 (just below $M_{D D}$ ). The drag-rise Mach will decrease with higher $C_{L}$ and also with higher airfoil thicknesses (Mair \& Birdsall, 1992; Nicolai \& Carichner, 2010; Shevell, 1989), and thus result in an earlier drag-divergence and significant influence of wave drag. That will also reduce maximum cruising speed, maximum range, and cruising aerodynamic efficiency (Daidzic, 2014b). For example, an airplane with cruise $C_{L}$ of about 0.3 may have $M_{D D}$ of about 0.87 , but as $C_{L}$ increases to 0.5 (e.g., in a constant-altitude turn), $M_{D D}$ decreases to about 0.82 .

As originally reported by Hilton (1952), Lock suggested an empirical functional relationship for the wave drag in the airspeed range above critical Mach number $\left(M \geq M_{C R}\right)$, i.e., $C_{D w}=20\left(M-M_{C R}\right)^{4}$ (Cavcar \& Cavcar, 2004; Filippone, 2012; Malone \& Mason, 1995; Mason, 2002). Using the above wave drag relationship and combining it with the definition of $M_{D D}$, it is calculated that $M_{D D}=M_{C R}+0.1077$. Accordingly, for $M_{D D}$ equal to 0.872 , the $M_{C R}$ is 0.765 , which is a reasonable value for a thin moderately swept wing (35) on a medium-haul transporter. The wave drag coefficient is 0.00269 at $C_{L}=0.4$. Our intent is thus to neglect wave drag entirely for cruise below $M_{M O}$ or $M_{D D}$, whichever is lesser. However, some discussion of wave drag effects on the maximum cruising airspeed will be included later.

Once the boundary layer separation due to shock-stall becomes significant, the wave drag due to lift cannot be reliably estimated with the quadratic dependence on $C_{L}$ (Mair \& Birdsall, 1992). The full effect of the wave drag and transonic effects warrants an article in itself and will indeed be incorporated in a future contribution. Deviations from the conventional drag polar do exist (Nicolai \& Carichner, 2010), but despite known imperfections it is still a very decent estimate. Thus, high-subsonic airspeed aerodynamic drag will be modeled using the conventional drag polar, while neglecting the small camber effect (Anderson, 1999; Ashley, 1992; Asselin, 1997; Bertin \& Cummings, 2009; Filippone, 2012; Hale, 1984; Nicolai \& Carichner, 2010; Phillips, 2004; Shevell, 1989; Vinh, 1993):

$$
C_{D}=C_{D 0}(M)+K(M) \cdot C_{L}^{2}
$$

The zero-lift drag coefficient $C_{D 0}$ is taken constant for airspeeds below $M_{D D}$, and the $C_{L}^{2}$ component includes both the viscous and the vortex drag components (Bertin \& Cummings, 2009; Nicolai \& Carichner, 2010) and was assumed as Mach-number independent for the same Mach range. A generic drag polar for airplane in clean and takeoff configuration is illustrated in Figure 1. Total drag is now a sum of drag not due to lift (mostly parasitic) and drag due 


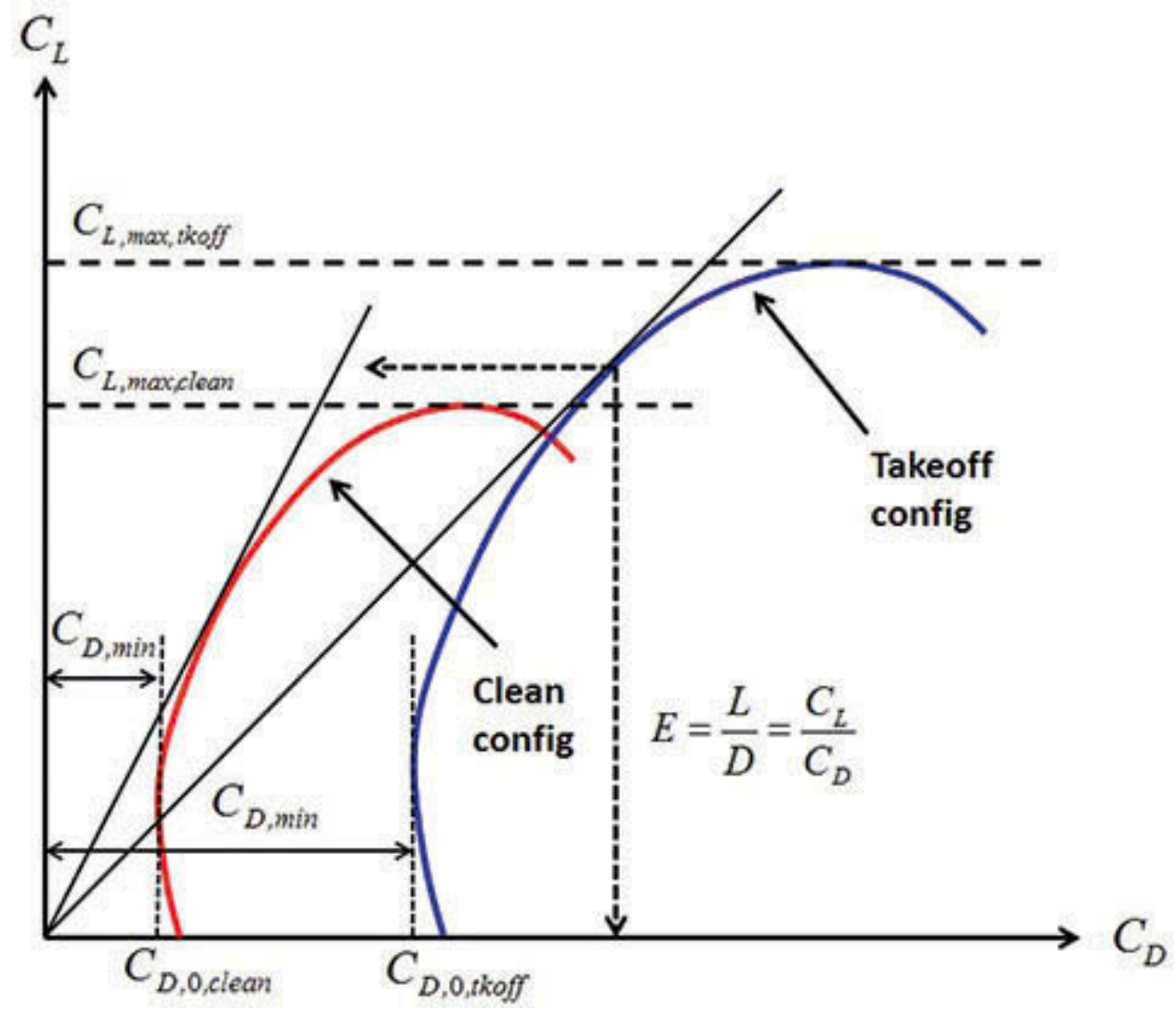

Figure 1. Typical parabolic drag polar for clean and flapped wing. Not to scale.

Table 1

Basic data for a large transport-category FAR/CS 25 medium to long-haul commercial subsonic airplane.

\begin{tabular}{cccccc}
\hline $\begin{array}{c}\text { MSTOW } \\
{[\mathbf{l b}]}\end{array}$ & MSLW [lb] & S [ $\left.\mathbf{f t}^{2}\right]$ & b [ft] & AR [-] & e [-] \\
\hline 400,000 & 320,000 & 3,100 & 156.0 & 7.85 & 0.90 (cruise) \\
\hline
\end{tabular}

to lift (mostly induced or vortex drag):

$$
D(\sigma, v)=\frac{1}{2} \sigma \rho_{S L} v^{2} S C_{D}=C_{p} v^{2}+C_{i} v^{-2}
$$

Where:

$$
\begin{aligned}
C_{p}=\frac{1}{2} \sigma \rho_{S L} S C_{D, 0} \quad C_{i} & =\frac{2 K S n^{2}}{\sigma \rho_{S L}} \cdot\left(\frac{W}{S}\right)^{2} \\
C_{i} & >>C_{p} \quad n=\frac{L}{W}
\end{aligned}
$$

Basic airframe data for a fictional T-category wide-body airplane used here is given in Table 1. From the basic geometric characteristic, the mean chord length is $19.87 \mathrm{ft}$ and the wing loading (W/S) is about $129 \mathrm{lb} / \mathrm{ft}^{2}$. Power required becomes:

$$
P_{r e q}(\sigma, v)=C_{p} v^{3}+C_{i} v^{-1}
$$

\section{Turbofan Thrust and Power Available}

Thrust of turbofan engines is a complicated function of many parameters. Turbofan engine models, based on a set of ordinary differential equations for each spool dynamic, exists (Jaw \& Mattingly, 2009; MacIsaac \& Langton, 2011; Walsh \& Fletcher, 1998), but inclusion of such time-dependent models would not be appropriate in this study. A conventional way to simulate turbofan thrust at maximum throttle settings is to consider it a function of environmental air density and forward (TAS) speed (Anderson, 1999; Daidzic, 2012; Mair \& Birdsall, 1992; McCormick, 1995):

$$
T_{a}(\sigma, v)=n_{e} N_{1} T_{0} \sigma^{m} \cdot\left(1+a_{1} v+a_{2} v^{2}\right) \quad T_{0}=T_{S L, I S A}^{\text {static }}
$$

Where:

$$
a_{1}=a_{1}(B P R)<0 \quad a_{2}=a_{2}(B P R)>0
$$

Rated thrust (Daidzic, 2012) and the density-exponent " $m$ " is (Daidzic, 2012; Mair \& Birdsall, 1992; McCormick, 1995):

$$
\begin{array}{r}
T_{0}=\left\{\begin{array}{cc}
\text { TOGA } & 5 \mathrm{~min} \\
\text { MCT } & \text { unlimited }
\end{array}\right\} \quad m=\left\{\begin{array}{cc}
0.7 & h<36,151 \mathrm{ft} \\
1.0 & h \geq 36,151 \mathrm{ft}
\end{array}\right\} \\
\text { and } \quad n_{e}=\left\{\begin{array}{c}
A E O \\
O E I
\end{array}\right\}
\end{array}
$$


The factor " $n_{e}$ " defines the number of engines during AEO conditions, while the number of engines is " $n_{e}-1$ " during OEI conditions. The actual thrust produced by a turbofan is a product of (maximum rated) thrust available and the TSP $\leq 1$ (Thrust/Throttle Setting Parameter). The relationship between the TSP and throttle position is typically nonlinear even for HBPR turbofan engines, but modern FADECs can linearize the curves digitally (Daidzic, 2012; Jaw \& Mattingly, 2009; Mattingly, 2005). A TSP is typically related to a low-pressure (fan) $N_{1} \%$ spool speed (for HBPR and UHBPR engines) or to an Engine Pressure Ratio (EPR) for low-BPR and mediumBPR engines. Thus, TSP is defined in terms of Takeoff Go-Around (TOGA) $N_{1}=N_{1} \% / 100$ as:

$$
N_{1}=\left\{\begin{array}{lc}
0.1-1.0 & \text { when TOGA } \\
0.1-0.9 & \text { when MCT }
\end{array}\right\}
$$

The Maximum Continuous Thrust (MCT) was set somewhat arbitrarily to $90 \%$ of TOGA. This parameter is called "throttle parameter" by Menon (1989). Even at idle setting a jet engine produces significant residual thrust. The thrust equation can be also given in terms of Mach number, $v=T A S=a_{S L} M \sqrt{\theta}$, and one obtains:

$$
\begin{array}{r}
T_{a}(\sigma, \theta, M)=n_{e} N_{1} T_{0} \sigma^{m} \cdot\left(1+b_{1} M \sqrt{\theta}+b_{2} M^{2} \theta\right) \\
b_{1}=a_{1} a_{S L}<0 \quad b_{2}=a_{2} a_{S L}^{2}>0
\end{array}
$$

Although this relationship is semi-empirically obtained from particular HBPR turbofan thrust measurements and data fitting, it nevertheless has sound physical foundation. Coefficients " $a$ " and " $b$ " account for momentum drag, which reduces net thrust and ram pre-compression effect which increases net thrust, respectively. Both coefficients are complicated and still unknown functions of BPR, TSP, rotor (spool) speeds, blade and combustor designs, inlet and nozzle design, and many other engine-component parameters which can only be estimated reliably by direct measurements and experimental identification. It is assumed here that aforementioned coefficients remain constant at both MCT and, typically, 5-10 minute TOGA thrust. Additionally, these coefficients are engine make and model specific and do not represent universal constants. Propulsive power delivered by a thrust-producing powerplant is now:

$P_{a}(\sigma, v)=v \cdot T_{a}(\sigma, v)=n_{e} N_{1} T_{0} \sigma^{m} \cdot\left(v+a_{1} v^{2}+a_{2} v^{3}\right)$
In terms of Mach number, Equation (10) becomes:

$$
\begin{array}{r}
P_{a}(\sigma, \theta, M)=n_{e} N_{1} T_{0} \sigma^{m} a_{S L} \\
\cdot\left(M \sqrt{\theta}+b_{1} M^{2} \theta+b_{2} M^{3} \theta^{3 / 2}\right)
\end{array}
$$

A very common TSFC relationship (Eshelby, 2000; Mair \& Birdsall, 1992; Mattingly, 2005) used in performance calculations is:

$$
\operatorname{TSFC}(\theta, M)=\frac{\dot{m}_{f}}{T}=T S F C_{r e f} \cdot \sqrt{\theta} \cdot M^{n}
$$

However, this relationship is not universally valid throughout the entire flight envelope. Nevertheless, Mair and Birdsall (1992) recommend the coefficient $n=0.48$, while Eshelby (2000) recommends $n=0.6$.

A new fuel law for turbojets and turbofans that covers the entire flight envelope of the engine from the lowest to the highest airspeeds continuously is proposed for the first time:

$$
\operatorname{TSFC}(\theta, M)=T \operatorname{SFC}_{0} \cdot \sqrt{\theta} \cdot(1+M)^{n}
$$

where,

$$
n=\left\{\begin{array}{cc}
0.2 & \text { Turbojet } \\
0.8 & \text { HBPR } \\
0.9 & \text { UHBPR }
\end{array}\right\}
$$

Here, $\mathrm{TSFC}_{0}$ corresponds to the static SL ISA installed thrust SFC at MCT. The value of $\mathrm{TSFC}_{0}$ for 90 's generation turbofans with BPRs around 5:1 is about 0.40 (lbf/hr/lbf or $\mathrm{kg} / \mathrm{hr} / \mathrm{daN}$ ) and is independent of thrust rating/ level (Mair \& Birdsall, 1992; McCormick, 1995). The exponent " $n$ " in Equation (12) depends on the engine internal design and layout, BPR, etc. The new model for TSFC proposed here (with $n=0.8$ ) agrees well with the measured data for the P\&W PW4056 engine (McCormick, 1995). Basic fictitious HBPR and UHBPR generic turbofan data used in this work are summarized in Table 2.

The HBPR and UHBPR turbofan thrust and TSFC as a function of Mach number and altitude modeled with Equations (10) and (13) are shown in Figures 2 and 3, respectively. As expected, thrust decreases significantly with the forward speed before it levels off at high Mnumbers due to the increasing ram effect. That decrease (momentum drag) is steeper for the UHBPR engine and the ram recovery is smaller. Thrust reduction with Mach speed

Table 2

Basic data for flat-rated turbofan engines used.

\begin{tabular}{ccccccc}
\hline Turbofan & T $_{\text {SL,static }}[\mathbf{l b}]$ TOGA/MCT & TSFC $_{\mathbf{0}}$ (MCT) [lb/lb-hr] & $\mathbf{n}$ & $\mathbf{a}_{\mathbf{1}}$ & $\mathbf{a}_{\mathbf{2}}$ \\
\hline HBPR & $60,000 / 54,000$ & 0.40 & 0.8 & $-8.500 \times 10^{-4}$ & $+5.500 \times 10^{-7}$ \\
UHBPR & $72,000 / 64,800$ & 0.32 & 0.9 & $-9.50 \times 10^{-4}$ & $+5.000 \times 10^{-7}$ \\
\hline
\end{tabular}




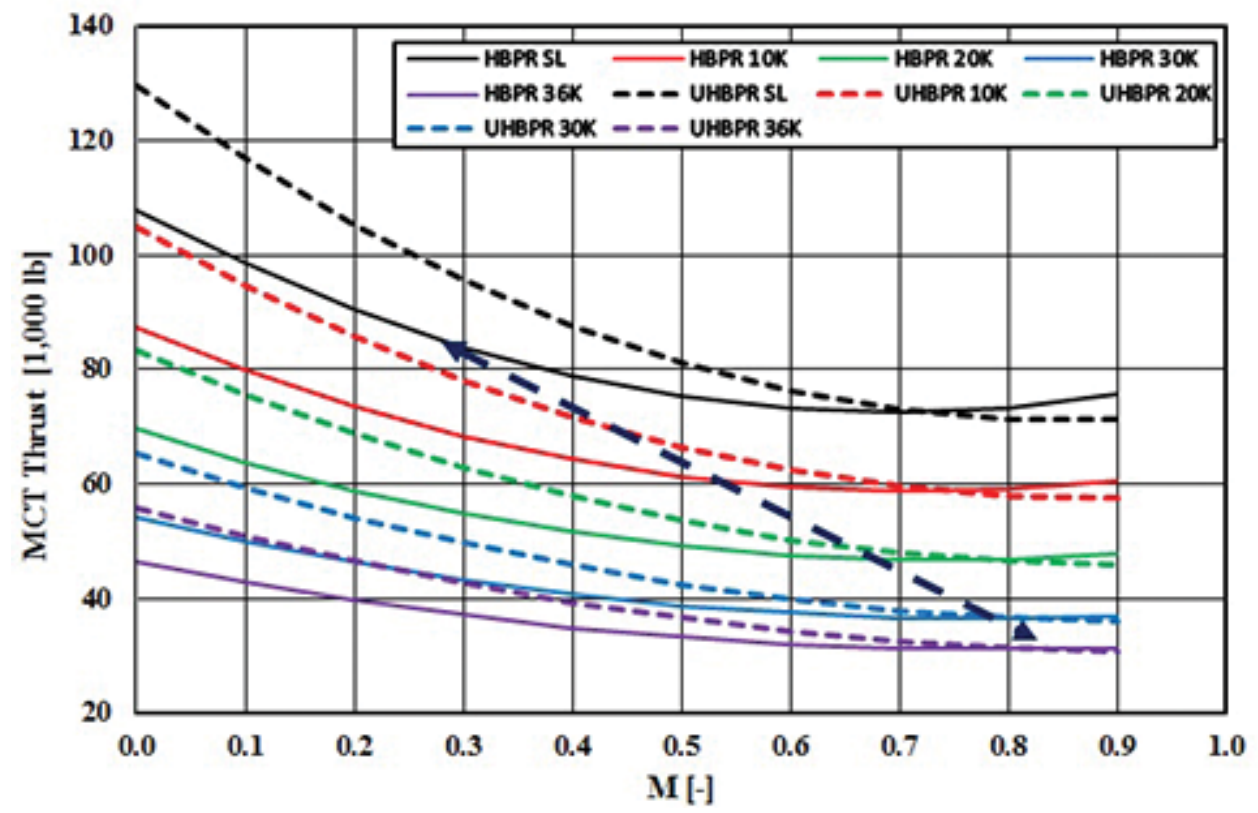

Figure 2. MCT as a function of Mach number and flight level (temperature) for HBPR and UHBPR turbofans. Dashed double arrow shows the approximate HBPR engine operational flight range $(m=0.7)$.

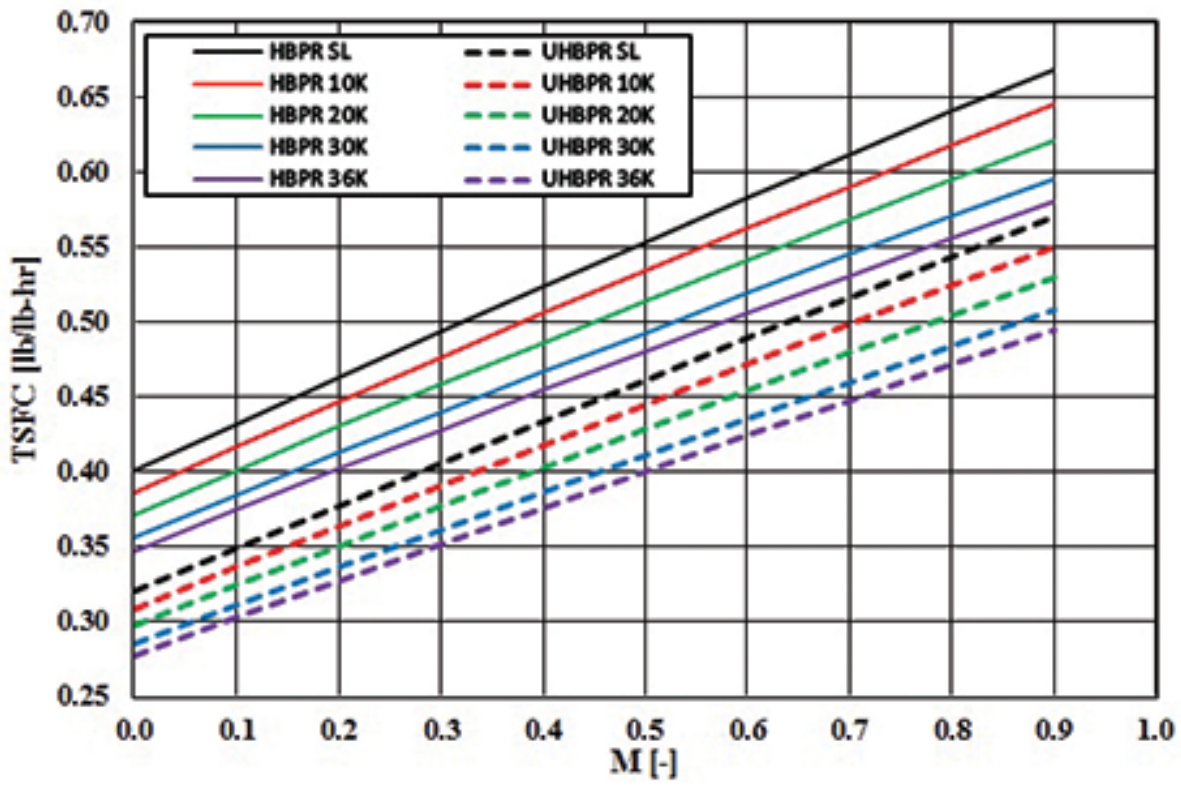

Figure 3. TSFC as a function of Mach number and flight level for HBPR and UHBPR turbofans.

decreases at high tropospheric altitudes (lower temperatures). All computations were performed for the ISA troposphere only using new computational ISA algorithms (Daidzic, 2015). In reality, an airplane would not be able to sustain flight at low airspeeds (e.g., $M<0.7$ ) and high altitudes due to aerodynamic stall (low-speed buffet) boundary (flight envelope). Thrust and TSFC model may not be accurate for very high subsonic airspeeds (e.g., $M>$ 0.90). As expected, TSFC increases with Mach number and decreases with altitude (temperature effect) as shown in Figure 3.

\section{Derivation of Control and Performance Airspeeds}

Selected important performance speeds will be now derived and defined using a systematic optimization method with one independent variable alone. Some critical airspeeds are solely airframe dependent, such as the control 
airspeeds, $V_{S}$ (power off or zero thrust), $V_{M D}$, and $V_{M P}$. Others are airframe-engine combination dependent, such as the performance airspeeds, $V_{X}, V_{E}, V_{Y}, V_{M R C}$, and the minimum- and maximum-propulsion level-cruise airspeed, $V_{M I N}$ and $V_{M A X}$. Change in stalling speed with Mach and Reynolds numbers is not modelled and every reference is to SL ISA stalling speed. To obtain the minimum-drag airspeed $\left(V_{M D}\right)$, one seeks to minimize the parabolic drag:

$$
\frac{\partial D(\sigma, v)}{\partial v}=0 \Rightarrow C_{p} v_{M D}-C_{i} v_{M D}^{-3}=0
$$

For the reasons that will become clear later, new constants are introduced and one obtains the final polynomial form for determination of minimum-drag airspeed as:

$$
A_{M D} \cdot v_{M D}^{4}+F_{M D}=0
$$

where:

$$
\begin{array}{lc}
A_{M D}=C_{p} & B_{M D}=0 \\
D_{M D}=0 & F_{M D}=-C_{i}
\end{array}
$$

This is a special case of the general $4^{\text {th }}$-order (quartic) polynomial:

$$
A \cdot x^{4}+B \cdot x^{3}+C \cdot x^{2}+D \cdot x+F=0
$$

Such polynomial of $4^{\text {th }}$-order (Equation 16) does not have a general closed-form analytic solution other than in some very special cases. Generally, such polynomial can have multiple real roots and at least one complexconjugate pair of roots. Naturally, one is only seeking real positive roots for airspeeds. Fortunately, Equation (15) can be solved analytically. Substituting values from Equation (5) one obtains for the real positive solution:

$$
\begin{aligned}
v_{M D} & =\left(\frac{C_{i}}{C_{p}}\right)^{1 / 4}=\left(\frac{2}{\rho_{S L}}\right)^{1 / 2}\left(\frac{1}{\sigma}\right)^{1 / 2}\left(\frac{W}{S}\right)^{1 / 2}\left(\frac{K}{C_{D, 0}}\right)^{1 / 4} \\
T A S_{M D} & =\frac{C A S_{M D}}{\sqrt{\sigma}}
\end{aligned}
$$

The maximum aerodynamic efficiency $E$ (flight load $n=1)$ and $K \neq K\left(C_{L}\right)$ is (Asselin, 1997):

$$
\begin{aligned}
\frac{\partial E}{\partial C_{L}}= & \frac{\partial}{\partial C_{L}}\left(\frac{C_{L}}{C_{D 0}+K \cdot C_{L}^{2}}\right)=0 \\
& \Rightarrow E_{\max }=\left(\frac{C_{L}}{C_{D}}\right)_{\max }=\frac{1}{\sqrt{4 C_{D, 0} K}}
\end{aligned}
$$

These are familiar classical solutions (e.g., Anderson, 1999; Mair \& Birdsall, 1992; Vinh, 1993). This air speed also corresponds to the maximum-endurance airspeed $v_{E}=v_{M D}$ for turbojets (speed-independent thrust). Minimum-power-required airspeed $\left(V_{M P}\right)$ is obtained by differentiating Equation (7):

$$
\frac{\partial P_{r}(\sigma, v)}{\partial v}=0 \quad \Rightarrow \quad 3 \cdot C_{p} v_{M P}^{2}-C_{i} v_{M P}^{-2}=0
$$

resulting in minimum-power airspeed:

$$
v_{M P}=\sqrt[4]{\frac{C_{i}}{3 C_{p}}}=\frac{1}{3^{1 / 4}} v_{M D} \approx 0.7598 \cdot v_{M D}
$$

This is also a familiar power-off minimum-sink airspeed that is of particular importance to gliders (sailplanes), but not so much for FAR/CS 25 T-category airplanes. Nonetheless, it represents another analytical solution that will be used to test the nonlinear equation solver. The polynomial form yields:

$$
A_{M P} \cdot v_{M P}^{4}+F_{M P}=0
$$

where:

$$
\begin{array}{lrr}
A_{M P}=3 \cdot C_{p} & B_{M P}=0 & C_{M P}=0 \\
D_{M P}=0 & F_{M P}=-C_{i} &
\end{array}
$$

Essential airframe-powerplant dependent performance airspeeds will be now derived in a systematic and consistent manner. A crucial operational performance airspeed is the airspeed for which the cruise range of turbojet airplane is maximized. This is especially important in various optimum cruise considerations (Daidzic, 2014b). The range factor (RF) is defined as $R F=(v / T S F C) \times(L / D)$ (Daidzic, 2014b). In the simple case when TSFC is airspeed-independent in un-accelerated straight-and-level flight, one needs to minimize the ratio:

$$
\begin{aligned}
\frac{\partial}{\partial v}\left[\frac{D(\sigma, v) \cdot T S F C}{v}\right] & =\frac{\partial}{\partial v}\left[\frac{D(\sigma, v)}{v}\right]=0 \\
\Rightarrow & C_{p}-3 \cdot C_{i} v_{M R C}^{-4}=0
\end{aligned}
$$

By utilizing Equation (17), the above condition results in:

$$
v_{M R C}=\sqrt[4]{\frac{3 C_{i}}{C_{p}}}=3^{1 / 4} v_{M D} \approx 1.316 \cdot v_{M D}
$$

This is also familiar maximum cruise range (MRC) airspeed for speed-independent TSFC turbojets (Daidzic, 2014b; Eshelby, 2000; Mair \& Birdsall, 1992). The general polynomial form yields:

$$
A_{M R C} \cdot v_{M R C}^{4}+F_{M R C}=0
$$

where:

$$
\begin{aligned}
& A_{M R C}=C_{p} \quad B_{M R C}=0 \quad C_{M R C}=0 \\
& D_{M R C}=0 \quad F_{M R C}=-3 \cdot C_{i}
\end{aligned}
$$

The aerodynamic efficiency at MRC corresponds to the maximum efficiency (Asselin 1997; Hale, 1984; Raymer 
1999, 2004; Saarlas, 2007):

$$
E_{M R C}=\frac{\sqrt{3}}{2} E_{\max }=0.866 \cdot\left(\frac{L}{D}\right)_{\max }
$$

The AEO or OEI airspeeds for the best-angle (steepestclimb) are found where the difference between the available (normally TOGA) and the required thrust is largest:

$$
\begin{aligned}
\Delta T(\sigma, v)= & n_{e} N_{1} T_{0} \sigma^{m} \cdot\left(1+a_{1} v+a_{2} v^{2}\right) \\
& -C_{p} v^{2}-C_{i} v^{-2}>0
\end{aligned}
$$

and

$$
\begin{gathered}
\frac{\partial[\Delta T(\sigma, v)]}{\partial v}=0 \Rightarrow n_{e} N_{1} T_{0} \sigma^{m} \cdot\left(a_{1}+2 \cdot a_{2} v_{X}\right) \\
-2 \cdot C_{p} v_{X}+2 \cdot C_{i} v_{X}^{-3}=0
\end{gathered}
$$

by designating:

$$
\begin{aligned}
& A_{X}=2 \cdot\left(n_{e} N_{1} T_{0} \sigma^{m} a_{2}-C_{p}\right) \quad B_{X}=n_{e} N_{1} T_{0} \sigma^{m} a_{1} \\
& C_{X}=0 \quad D_{X}=0 \quad F_{X}=2 \cdot C_{i}=\frac{4 K S n^{2}}{\sigma \rho_{S L}} \cdot\left(\frac{W}{S}\right)^{2}
\end{aligned}
$$

the following polynomial form is obtained:

$$
f\left(v_{X}\right)=A_{X} v_{X}^{4}+B_{X} v_{X}^{3}+F_{X}=0
$$

This algebraic equation has no known analytical solution and must be solved numerically. If one normalizes all airspeeds in reference to the stalling airspeed, the modified equation yields:

$$
f\left(\bar{v}_{X}\right)=A_{X}^{\prime} \bar{v}_{X}^{4}+B_{X}^{\prime} \bar{v}_{X}^{3}+F_{X}^{\prime}=0 \quad \bar{v}_{X}=\frac{v_{X}}{v_{S}}
$$

By adjusting the number of engines parameter " $n_{e}$," the AEO and OEI performance figures can be predicted. The steepest-climb airspeed $V_{X}$ is identical to the local maximum-endurance $V_{E}$ airspeed (at constant altitude). Accordingly, one has:

$$
\frac{\partial D\left(\sigma, v_{E}\right)}{\partial v}=\frac{\partial T\left(\sigma, v_{E}\right)}{\partial v}
$$

This results in an identical nonlinear problem already given above by Equations (27) and (28). Unlike the situation in which thrust is assumed speed-independent and where $V_{X}$ and $V_{E}$ are identical and also coinciding with $V_{M D}$, for speed-dependent thrust in HBPR/UHBPR turbofans $V_{X}=V_{E}$ airspeeds will be actually slower than $V_{M D}$. To get the global maximum endurance, other constraints and complete TSFC envelope need to be considered.

The speed for maximum or best rate of climb speed $V_{Y}$, is found where the excess power is maximized:

$$
\begin{aligned}
\Delta P(\sigma, v)= & n_{e} N_{1} T_{0} \sigma^{m} \cdot\left(v+a_{1} v^{2}+a_{2} v^{3}\right) \\
& -C_{p} v^{3}-C_{i} v^{-1}>0
\end{aligned}
$$

The extreme of the excess power equation delivers yet another polynomial that cannot be solved analytically:

$$
\begin{aligned}
\frac{\partial[\Delta P(\sigma, v)]}{\partial v}= & 0 \Rightarrow n_{e} N_{1} T_{0} \sigma^{m} \\
& \cdot\left(1+2 \cdot a_{1} v_{Y}+3 \cdot a_{2} v_{Y}^{2}\right) \\
& -3 \cdot C_{p} v_{Y}^{2}+C_{i} v_{Y}^{-2}=0
\end{aligned}
$$

If one designates:

$$
\begin{array}{ll}
A_{Y}=3 \cdot\left(n_{e} N_{1} T_{0} \sigma^{m} a_{2}-C_{p}\right) & B_{Y}=2 \cdot n_{e} N_{1} T_{0} \sigma^{m} a_{1} \\
C_{Y}=n_{e} N_{1} T_{0} \sigma^{m} \quad D_{Y}=0 & F_{Y}=C_{i}=\frac{2 K S n^{2}}{\sigma \rho_{S L}} \cdot\left(\frac{W}{S}\right)^{2}
\end{array}
$$

The nonlinear polynomial form results:

$$
f\left(v_{Y}\right)=A_{Y} v_{Y}^{4}+B_{Y} v_{Y}^{3}+C_{Y} v_{Y}^{2}+F_{Y}=0
$$

Introducing the non-dimensional maximum-rate velocity, the modified equation yields:

$f\left(\bar{v}_{Y}\right)=A_{Y}^{\prime} \bar{v}_{Y}^{4}+B_{Y}^{\prime} \bar{v}_{Y}^{3}+C_{Y}^{\prime} \bar{v}_{Y}^{2}+F_{Y}^{\prime}=0 \quad \bar{v}_{Y}=\frac{v_{Y}}{v_{S}}(34)$

The last performance speed discussed here is the maximum (propulsion limit) level flight speed achieved at MCT. In this first consideration, wave drag is neglected. For the condition of maximum (and minimum propulsionlimited) cruise speed we have the mathematical condition:

$$
\begin{aligned}
T\left(\sigma, v_{M}\right) & =D\left(\sigma, v_{M}\right) \\
& \Rightarrow n_{e} N_{1} T_{0} \sigma^{m} \cdot\left(1+a_{1} v_{M}+a_{2} v_{M}^{2}\right) \\
& =C_{p} v_{M}^{2}+C_{i} v_{M}^{-2}
\end{aligned}
$$

Designating:

$$
\begin{aligned}
& A_{M}=\left(n_{e} N_{1} T_{0} \sigma^{m} a_{2}-C_{p}\right) \quad B_{M}=n_{e} N_{1} T_{0} \sigma^{m} a_{1} \\
& C_{M}=n_{e} N_{1} T_{0} \sigma^{m} \quad D_{M}=0 \\
& F_{M}=-C_{i}=-\frac{2 K S n^{2}}{\sigma \rho_{S L}} \cdot\left(\frac{W}{S}\right)^{2}
\end{aligned}
$$


Table 3

Aerodynamic data for the fictitious large T-category FAR/CS 25 commercial subsonic airplane. Landing configuration also includes landing gear extended drag.

\begin{tabular}{cccc}
\hline Configuration & Clean/Cruise (I) & Takeoff $($ Gear up) (II) & Landing (III) \\
\hline$C_{D, 0}$ & 0.020 & 0.035 & 0.135 \\
$C_{L, \max }$ & 1.65 & 2.20 & 3.00 \\
$K$ & 0.045 & 0.050 & 0.055 \\
$E_{\max }=(L / D)_{\max }$ & 16.67 & 11.95 & 5.80 \\
$V_{M D} / V_{S}$ & 1.5732 & 1.6216 & 1.3838 \\
$V_{M P} / V_{S}$ & 1.1954 & 1.2321 & 1.0514 \\
$V_{M R C} V_{S}$ & 2.0705 & 2.1341 & 1.8212 \\
\hline
\end{tabular}

results in:

$$
f\left(v_{M}\right)=A_{M} v_{M}^{4}+B_{M} v_{M}^{3}+C_{M} v_{M}^{2}+F_{M}=0
$$

By introducing the non-dimensional maximum velocity the modified equation is obtained:

$f\left(\bar{v}_{M}\right)=A_{M}^{\prime} \bar{v}_{M}^{4}+B_{M}^{\prime} \bar{v}_{M}^{3}+C_{M}^{\prime} \bar{v}_{M}^{2}+F_{M}^{\prime}=0 \quad \bar{v}_{M}=\frac{v_{M}}{v_{S}}$

Unlike in previous cases, one is seeking two real positive solutions of Equations (36) and (37). Thus, $v_{M}$ can be either of the two level-flight propulsion-limited airspeeds, i.e., $V_{M A X}$ or $V_{M I N}$. In reality none of the $v_{M}$ 's may be achievable or due to stall speed limit on the lower end or $V_{M O} / M_{M O}$ limit on the higher end. Subsequent calculations will show that all $V_{M I N}$ here are indeed slower than appropriate stalling speeds and thus are irrelevant.

Many useful conclusions can be made about the nature of the roots of the derived polynomials depending on the sign and magnitude of its coefficients. However, such complex mathematical analysis is beyond the scope of this article.

Essential drag and performance data for a fictitious T-category airplane is summarized in Table 3. Interestingly, $V_{M D} / V_{S}, V_{M P} / V_{S}$, and $V_{M R C} / V_{S}$ ratios are independent of altitude and weight and are only configuration dependent for not too high Mach numbers:

$$
\begin{aligned}
\frac{v_{M D}}{v_{S}} & =\left(\frac{K \cdot C_{L, \max }^{2}}{C_{D, 0}}\right)^{1 / 4} \quad \frac{v_{M P}}{v_{S}}=\left(\frac{1}{3}\right)^{1 / 4}\left(\frac{v_{M D}}{v_{S}}\right) \\
\frac{v_{M R C}}{v_{S}} & =3^{1 / 4}\left(\frac{v_{M D}}{v_{S}}\right)
\end{aligned}
$$

\section{Sensitivity of Airspeed Estimations on Drag Data}

An important question arises as to how sensitive airspeed estimation based on the set of geometric and aerodynamic data is. Such an analysis would warrant an article in itself. Thus only the analysis of minimum-drag speed and the maximum aerodynamic efficiency will be addressed here. A simple parabolic drag polar is assumed with constant coefficients. The effect of density and wing loading is not to be addressed, but could be easily included. Using
$v_{M D}=f\left(C_{D, 0}, K\right)$ describes drag-data dependence, the small perturbations can be described as:

$\frac{\boldsymbol{\Delta}\left(v_{M D}\right)}{v_{M D}}=\left[\frac{\partial\left(v_{M D}\right)}{\partial\left(C_{D, 0}\right)}\right]_{K} \frac{\boldsymbol{\Delta}\left(C_{D, 0}\right)}{v_{M D}}+\left[\frac{\partial\left(v_{M D}\right)}{\partial K}\right]_{C_{D, 0}} \frac{\Delta K}{v_{M D}}$

Thus, an analysis of TAS is analog of CAS/EAS analysis as density ratio is assumed constant. Evaluating and substituting partial derivatives and utilizing Equation (17) yields:

$$
\frac{\Delta\left(v_{M D}\right)}{v_{M D}}=-\frac{1}{4} \frac{\Delta\left(C_{D, 0}\right)}{C_{D, 0}}+\frac{1}{4} \frac{\Delta K}{K}
$$

Similarly, the small perturbation (total differential) for the maximum aerodynamic efficiency (Equation 18), now yields:

$$
\begin{aligned}
\frac{\Delta\left(E_{\max }\right)}{E_{\max }} & =\left[\frac{\partial\left(E_{\max }\right)}{\partial\left(C_{D, 0}\right)}\right]_{K} \frac{\boldsymbol{\Delta}\left(C_{D, 0}\right)}{E_{\max }}+\left[\frac{\partial\left(E_{\max }\right)}{\partial K}\right]_{C_{D, 0}} \frac{\Delta K}{E_{\max }} \\
& =-\frac{1}{2} \frac{\boldsymbol{\Delta}\left(C_{D, 0}\right)}{C_{D, 0}}-\frac{1}{2} \frac{\boldsymbol{\Delta} K}{K}
\end{aligned}
$$

Accordingly, a $10 \%$ increase in zero-lift parasitic drag coefficient will cause $2.5 \%$ decrease in minimum-drag airspeed and $5 \%$ decrease in maximum aerodynamic efficiency. On the other hand a $10 \%$ increase in induceddrag coefficient will cause $2.5 \%$ increase in minimum-drag airspeed and 5\% decrease in maximum aerodynamic efficiency. The above theoretical consideration is a mathematical proof that increased parasitic drag $\left(C_{D, 0}\right)$ moves $V_{M D}$ to lower, while increased induced drag $(K)$ moves $V_{M D}$ to higher airspeeds. While $V_{M D}$ is quite insensitive to small drag changes, the aerodynamic efficiency is moderately so. This is important as cruise fuel consumption is inversely proportional to the cruise aerodynamic efficiency. Also obvious from Equation (17) is the well-known fact that increased wing loading moves the $V_{M D}$ toward higher speeds.

Similarly, numerical sensitivity and uncertainty analysis could be performed for estimation of all performance speeds. However, no simple analytic solutions exist then, 
and the full multi-parameter numerical analysis must be performed to observe effects of each parameter and drag coefficient. Such numerical analysis is not difficult, as the software programs have been designed, but it is just too time consuming and there is no space for it in this article.

\section{Maximum Cruise Airspeed Estimation in the Presence of Wave Drag}

To analyze the effect that transonic wave drag may have on the propulsion-limited maximum cruising speed, the general expression of wave-drag coefficient as a function of Mach number and coefficient-of-lift (Vallone, 2010) is used:

$$
C_{D w}\left(M, C_{L}\right)=a \cdot\left\{\left[M-M_{C R}\left(C_{L}\right)\right]+b \cdot\left(C_{L}-C_{L, 0}\right)^{c}\right\}^{d}
$$

Consulting many references (e.g., Mair \& Birdsall, 1992; Malone \& Mason, 1995; Shevell, 1989) and using the actual measurements on, somewhat older, existing highsubsonic airplanes (such as B747-100, DC-10, etc.), an approximate wave-drag relationship for not too large Mach numbers and not too strong shock waves for a fictitious airplane used here is proposed:

$$
\begin{aligned}
& C_{D w}\left(M, C_{L}\right) \\
& \quad=20\left\{\left[M-M_{C R}\left(C_{L}\right)\right]+5 \times 10^{-3}\left(C_{L}-C_{L, 0}\right)^{1 / 2}\right\}^{4}, \\
& C_{L, 0}=0, \quad M \leq M_{D D}\left(C_{L}\right)
\end{aligned}
$$

The dependence of drag-rise Mach number on coefficient-of-lift is expressed with an approximate semiempirical equation:

$$
M_{D D}\left(C_{L}\right)=M_{D D}\left(C_{L}=0\right)-\left(\frac{b}{\cos ^{3} \psi}\right) \cdot C_{L}
$$

This is the same relationship as the one given by Equation (4). Let us assume high-subsonic airplane cruise condition at $C_{L}=0.4, \quad t / \bar{c}=0.12, \quad b=0.14, \quad \psi=35^{\circ}, \quad C_{D, 0}=0.0175$, $K=0.045, M_{C R}=0.7347$, and $M_{D D}=0.8424$. The wavedrag coefficient from Equation (42) for the range $M_{C R}<0.84<M_{D D}$ and given $C_{L}$ becomes 0.002770 . The total drag coefficient (Equation 3) is:

$$
\begin{aligned}
C_{D} \approx & C_{D 0}+K \cdot C_{L}^{2}+C_{D w}=0.0175+0.045 \times 0.4^{2} \\
& +0.002770=0.027470
\end{aligned}
$$

In this particular example, the wave drag is about $10 \%$ of the total drag, which is a reasonably realistic estimate at high Mach numbers close to $M_{D D}$. This value and other calculations performed are in good agreement with the results presented in Mair and Birdsall (1992) and Shevell (1989) for wide-body airplanes. The transonic wave drag physics is extremely complicated and it would be excessively optimistic to assert that a simple algebraic equation could capture such complex phenomena in its entirety. However, for Mach numbers between the critical and the drag-divergence numbers, the functional relationships (Equations 42 and 43) are reasonably good for contemporary high-subsonic airplanes. We are predominantly interested in developing sound and consistent methodology, which can assist conceptual designs and first optimizations.

Computation of the maximum propulsion-limited cruise airspeed can now be conducted including considerations of the wave drag. However, this requires special effort and will be presented in a separate publication. It is quite clear that the maximum speeds in the presence of wave drag will be noticeably slower than when the wave drag is neglected. Typically, the maximum cruising straight-and-level airspeeds will be between the critical and the drag-divergence Mach numbers and actually closer to $M_{D D}$ than to $M_{C R}$.

\section{Methodology}

To calculate the unknown airspeeds derived earlier, one needs to resort to numerical methods for finding roots (zeroes) of general nonlinear equations and polynomials in particular. Considering that, generally, one may have, at least, one pair of complex-conjugate roots in quartic equations, which cannot be accepted on physical grounds; one could resort to specialized numerical methods that search for all roots. For example, Mueller's and Bairstow's methods (Chapra \& Canale, 2006; Press, Teulkolsky, Vetterling, \& Flannery, 1992) are classical techniques for finding real (with multiplicity) roots and complex-conjugate roots (always come in pairs), as used in many computer programing numerical libraries (Chapra \& Canale, 2006). More advanced techniques implemented in IMSL for Fortran numerical libraries utilize the Jenkins-Traub algorithm from 1970 (Press et al., 1992) and very efficient Laguerre's methods for finding complex conjugate and real multiple roots (Press et al., 1992). These methods are very complex and designed for global localization and root calculation and thus impractical for use here.

We are only interested in localizing and computing positive real roots in the vicinity of analytically evaluated stall and/or minimum-drag airspeeds. Therefore, a simple Newton-Raphson (NR) method with initial guess located at $V_{S}$ (or at $V_{M P}, V_{M D}$, or $V_{M R C}$ ) is employed. NR methods are also easily implemented in manual computations. However, this is not recommended for a large number of computations as performed here. Nonetheless, it is not difficult to encode NR method in any high-level programming language.

The NR method can be easily derived from the convergent Taylor-series continuous function expansion resulting in (Demidovich \& Maron, 1987):

$$
v_{j+1}=v_{j}-\frac{f\left(v_{j}\right)}{f^{\prime}\left(v_{j}\right)} \quad v_{0}=v_{S} \quad j=0,1,2, \ldots
$$

Differentiation of polynomials is trivial, and NR method is a good choice when analytical functions are known. The NR 
method converges quadratically, i.e., very rapidly (Carnahan, Luther, \& Wilkes, 1969; Chapra \& Canale, 2006; Conte \& de Boor, 1986; Demidovich \& Maron, 1987; Press et al., 1992; Ralston \& Rabinowitz 1978). However, global convergence is not guaranteed and the initial guess must be chosen properly.

As an example of numerical solution, the propulsionlimited minimum and maximum level cruise airspeeds, using the regular NR method yields:

$$
\begin{aligned}
v_{M, j+1} & =v_{M, j}-\frac{A_{M} v_{M . j}^{4}+B_{M} v_{M, j}^{3}+C_{M} v_{M, j}^{2}+F_{M}}{4 A_{M} v_{M, j}^{3}+3 B_{M} v_{M, j}^{2}+2 C_{M} v_{M, j}} \\
v_{M, 0} & =v_{S}, v_{M D}, \text { or } v_{M R C}
\end{aligned}
$$

Other derived airspeeds are calculated in a similar manner. One of the problems with the regular NR method is that it is only linearly convergent in the case of multiple roots $(r>1)$. If we know the number of root multiplicity " $r$," then according to Ralston and Rabinowitz (1978) and Chapra and Canale (2006), the modified procedure yields:

$$
\begin{gathered}
v_{j+1}=v_{j}-r \cdot \frac{f\left(v_{j}\right)}{f^{\prime}\left(v_{j}\right)} \quad v_{0}=v_{S} \\
j=0,1,2, \ldots \quad r=1,2,3, \text { or } 4
\end{gathered}
$$

However, if one does not know the root multiplicity in advance (which we often do not), then the modified Newton-Raphson (MNR) method (Chapra \& Canale, 2006) will insure quadratic convergence at the expense of a substantially more complicated algorithm (need for the analytic $2^{\text {nd }}$ derivative):

$$
\begin{gathered}
v_{j+1}=v_{j}-\frac{f\left(v_{j}\right) \cdot f^{\prime}\left(v_{j}\right)}{\left[f^{\prime}\left(v_{j}\right)\right]^{2}-f\left(v_{j}\right) \cdot f^{\prime \prime}\left(v_{j}\right)} \\
v_{0}=v_{S} \quad j=0,1,2, \ldots
\end{gathered}
$$

Quadratic convergence ensures rapid estimation of real roots if the initial guess is correctly chosen. In order to reduce the number of computations a method proposed by Demidovich and Maron (1987) can be used in which the first derivative (slope) in regular NR method is fixed at the initial slope. The convergence is slower, but the number of derivative function computations is sometimes substantially reduced:

$$
v_{j+1}=v_{j}-\frac{f\left(v_{j}\right)}{f^{\prime}\left(v_{0}\right)} \quad v_{0}=v_{S} \quad j=0,1,2, \ldots
$$

Several control and performance airspeeds are numerically computed using all four variations of the NR numerical root-finding method. Convergence and accuracy tests were conducted using analytically-derived airspeeds (e.g., $V_{M D}$ ). Results are obtained as TAS, CAS, EAS, or M speeds. Theoretical Pitot-tube compressibility correction can be used to calculate EAS from CAS (Padilla, 1996).
However, it must be emphasized that NR/MNR failed to converge to appropriate real root, with the initial estimate being corresponding stalling speed. Even by choosing the minimum-drag (or minimum-power) airspeed as the starting point of iterations, the convergence was not attained in all cases considered. There is no space available to give detailed account of convergence problems for each particular case. Curiously, when considering maximum and minimum propulsion-limit speeds, sometimes the initial guess at the minimum-drag or at the stalling speed resulted in locking into negative real roots and neither minimum- or maximum-propulsion speed was ever located. This is because the polynomial was rather flat in respective region and the slope shallow resulting in the first iteration landing on the negative airspeed side and remaining locked there. Graphical and tabular representation of functions was very helpful to monitor the convergence process. Thus, initial bracketing or locating regions of function sign change for all real roots was necessary to assure global convergence. We were not interested in complex-conjugate pairs or in negative real roots. Making the root-search model global complicates computations and contradicts one of stated goals to design a simple numerical procedure.

\section{Testing and Validation of the Numerical Method}

Generally, various polynomial forms for performance airspeeds derived here could result in negative-real, as well as one pair of complex-conjugate, roots which all must be discarded due to physical impossibility. Therefore, only the real positive solutions will be kept, which due to the physics of the problem lies between the stall and the maximum propulsion-limited airspeeds. The numerical root-finding algorithm utilizing NR/MNR methods is first tested against the analytically derived minimum-drag, minimum-power, and maximum-range airspeeds.

As the test bed for numerical computations, the airplane similar in characteristics to popular twin-engine B767300ER was used. The HBPR powerplant similar to GE CF6-80C2, RR RB211-524G/H, or P\&W PW4056/4060/ 4062 turbofan engines was used. The second powerplant is a fictional UHBPR used to explore the effects of increased BPR on performance airspeeds. Due to the inability to obtain the exact airframe aerodynamic force and moment coefficients as well as engine thrust/TSFC data, much of which is manufacturer's proprietary information, relevant experience, references, expert knowledge, and familiarity with various airplane engine types were used to construct approximate airframe and engine data. It must be reiterated again that primary interest here is in developing a methodology rather than predicting performance of any particular existing airframe and/or powerplant. Various essential airframe and powerplant data used for calculations were already given in Tables 1, 2, and 3 . 
Test and validation of the NR/MNR computational methods were first performed by numerically evaluating $V_{M D}, V_{M P}$, and $V_{M R C}$ airspeeds and comparing them to analytical solutions. Indeed, all the computations performed flawlessly and numerical computations converged to exact ones in few iterations only (typically 2 to 6), with 8 significant digits accuracy. The number of iterations was based on the absolute error (compared to analytical solution) being less than $10^{-6}$. The corresponding power-off stalling speed was used as a starting point typically resulting in rapid convergence. A large number of computations on the order of 150 hours were used for testing and obtaining relevant results. Development and testing of various software programs took a similar amount of time.

Microsoft Excel ${ }^{\mathrm{TM}}$ was used to calculate all AEO and OEI performance airspeeds as a function of weight and altitude. A spreadsheet program was also used for plotting all results. Additionally, we compared all spreadsheet calculations using the in-house developed root-finding programs written in Fortran 95. We used a standard ISO/ IEC 1539-1:1997 high-performance optimizing compiler by Lahey Computer Systems ${ }^{\mathrm{TM}}$. In-house developed Fortran 95 subroutines for real-root seeking employed nonlinear function solvers based on several bracketing numerical rootfinding open methods (Carnahan et al., 1969; Conte \& de Boor, 1986; Chapra \& Canale, 2006), such as Regula-Falsi, secant, fixed-point iteration, and regular Newton-Raphson
(NR). Of these, the NR method converged most rapidly and is especially suitable when the analytic polynomial expressions exist, from which derivatives are easily obtained.

Moreover, we utilized, validated, and tested our in-house written Fortran 95 subprograms with the licensed professional root-finding (nonlinear equations solvers) subprograms contained in IMSL (International Mathematical and Statistical Libraries, ver. 4.01 by Visual Numerics ${ }^{\mathrm{TM}}$ ) and SSL II (Scientific Subroutine Libraries II by Fujitsu ${ }^{\mathrm{TM}}$ ). We also utilized Numerical Recipes ${ }^{\odot}$ for Fortran $77 / 90$ numerical libraries (Press et al., 1992), which were written in standard ISO/IEC 1539:1991 Fortran 90 to test our Fortran 95 programs/subroutines. Matlab ${ }^{\mathrm{TM}}$ intrinsic numerical library programs were also used to test results. All various tests and verifications performed flawlessly and returned exactly the same values of polynomial roots (real and/or complex) with accuracy going up to double precision (15 significant digits).

As a particular example, the polynomial defining $V_{M D}$ (Equation 15) has four roots of which one is often real positive, one is real negative (of the same magnitude), and the remaining roots are a pair of complex-conjugate roots with the real part zero and non-zero conjugate-imaginary parts.

The test results for various airplane configurations are presented in Tables 4 and 5 at maximum structural takeoff weight (MSTOW) and maximum structural landing weight $(\mathrm{MSLW})$ for SL ISA $(\mathrm{TAS}=\mathrm{CAS}=\mathrm{EAS})$. Numerical

Table 4

Analytical and numerical computation of some control/performance airspeeds for various airplane configurations at MSTOW and SL with initial guess at stalling airspeeds.

\begin{tabular}{|c|c|c|c|}
\hline Configuration & Clean/Cruise (I) & Takeoff (II) & Landing (III) \\
\hline Analytical $V_{S}$ [fps/kts] & $256.51 / 151.91$ & $222.15 / 131.56$ & $190.23 / 112.66$ \\
\hline Analytical $V_{M P}[\mathrm{fps} / \mathrm{kts}]$ & $306.63 / 181.59$ & $273.71 / 162.09$ & $200.02 / 118.45$ \\
\hline Numerical $V_{M P}$ (\# of iterations) & $\begin{array}{c}306.63 / 181.59 \\
(2-3)\end{array}$ & $\begin{array}{c}273.71 / 162.09 \\
(3-4)\end{array}$ & $\begin{array}{c}200.02 / 118.45 \\
(2-3)\end{array}$ \\
\hline Analytical $V_{M D}$ [fps/kts] & $403.55 / 238.98$ & $360.23 / 213.33$ & $263.24 / 155.89$ \\
\hline Numerical $V_{M D}$ (\# of iterations) & $\begin{array}{c}403.55 / 238.98 \\
(4-5)\end{array}$ & $\begin{array}{c}360.23 / 213.33 \\
(5-6)\end{array}$ & $\begin{array}{c}263.24 / 155.89 \\
(5-6)\end{array}$ \\
\hline Analytical $V_{M R C}[\mathrm{fps} / \mathrm{kts}]$ & $531.10 / 314.52$ & $474.09 / 280.75$ & $346.45 / 205.17$ \\
\hline Numerical $V_{M R C}$ (\# of iterations) & $\begin{array}{c}531.10 / 314.52 \\
(5-7)\end{array}$ & $\begin{array}{c}474.09 / 280.75 \\
(6-8)\end{array}$ & $\begin{array}{c}346.45 / 205.17 \\
(5-6)\end{array}$ \\
\hline
\end{tabular}

Table 5

Analytical and numerical computation of some control/performance airspeeds for various airplane configurations at MSLW and SL with initial guess at stalling airspeeds.

\begin{tabular}{|c|c|c|c|}
\hline Configuration & Clean/Cruise (I) & Takeoff (II) & Landing (III) \\
\hline Analytical $V_{S}[\mathrm{fps} / \mathrm{kts}]$ & $229.43 / 135.87$ & 198.69/117.67 & $170.15 / 100.76$ \\
\hline Analytical $V_{M P}[\mathrm{fps} / \mathrm{kts}]$ & $274.26 / 162.42$ & $244.82 / 144.98$ & $178.91 / 105.95$ \\
\hline Numerical $V_{M P}$ (\# of iterations) & $\begin{array}{c}274.26 / 162.42 \\
(2-3)\end{array}$ & $\begin{array}{c}244.82 / 144.98 \\
(3-4)\end{array}$ & $\begin{array}{c}178.91 / 105.95 \\
(2-3)\end{array}$ \\
\hline Analytical $V_{M D}[\mathrm{fps} / \mathrm{kts}]$ & $360.94 / 213.75$ & $322.20 / 190.81$ & $235.45 / 139.44$ \\
\hline Numerical $V_{M D}$ (\# of iterations) & $\begin{array}{c}360.94 / 213.75 \\
(4-5)\end{array}$ & $\begin{array}{c}322.20 / 190.81 \\
(5-6)\end{array}$ & $\begin{array}{c}235.45 / 139.44 \\
(5-6)\end{array}$ \\
\hline Analytical $V_{M R C}[\mathrm{fps} / \mathrm{kts}]$ & $475.03 / 281.31$ & $424.03 / 251.11$ & $309.87 / 183.51$ \\
\hline Numerical $V_{M R C}$ (\# of iterations) & $\begin{array}{c}475.03 / 281.31 \\
(4-5)\end{array}$ & $\begin{array}{c}424.03 / 251.11 \\
(5-7)\end{array}$ & $\begin{array}{c}309.87 / 183.51 \\
(5-6)\end{array}$ \\
\hline
\end{tabular}


computations using all four (regular and modified) NR methods were utilized. Many additional tests and sensitivity analyses using various initial guesses with speeds slower and faster than analytical minimum-drag speed (or stalling speed) were performed in order to check the robustness and the convergence range. All computations converged rapidly to the analytical values of $V_{M D}$ and $V_{M P}$. However, very low starting speeds $\left(<100 \mathrm{ft} / \mathrm{s}\right.$, i.e., below $\left.V_{S}\right)$ resulted in more iterations $(>10)$ as the polynomials are rather flat in that region. Additionally, the computations did not converge in some instances for initial guesses less than 40-60 fps (quite below $V_{S}$ and unrealistic). Initial guesses faster than $V_{M D}$ (up to $1000+$ fps essentially exceeding $V_{M O} / M_{M O}$ ) often resulted in very rapid convergence $(<4$ iterations) due to rather monotonic and steep function growth in that region. Polynomials of $V_{M D}, V_{M P}$, and, $V_{M R C}$ were plotted in each case for visual inspection.

\section{Pénaud Aircraft Performance Diagrams}

Aircraft performance diagrams are often called Pénaud diagrams after the French engineer who was apparently the first to construct them in the 19th century. Airplane

Table 6

Airplane configuration and thrust levels used for computation of performance airspeeds.

\begin{tabular}{ccc}
\hline Airspeed & Airplane configuration & Thrust rating \\
\hline$V_{2}, V_{X}$ & Takeoff (II) & TOGA 5 min. \\
$V_{Y}, V_{M R C}, V_{M A X}$ & Cruise (I) & MCT \\
\hline
\end{tabular}

configurations and thrust ratings used here are summarized in Table 6. The AEO and OEI thrust-available curves at MCT and TOGA (5 min) thrust are plotted against drag (thrust required) curves at SL ISA for MSTOW and MSLW and are shown here in Figures 4 and 5. We did not account for additional drag due to rudder deflection and slight bank angle into the operating engine(s) required for airplane zerosideslip directional control with asymmetric OEI thrust. Similarly, the AEO and OEI power-available curves are plotted against the total-drag power (power required) curves, also at SL ISA for MSTOW and MSLW and shown here in Figures 6 and 7.

A twin-engine FAR/CS 25 airplane is not designed to climb at MSLW in landing configuration with OEI TOGA thrust. Instead, regulations require that twin-engine FAR/CS 25 airplane demonstrate gross $2.1 \%$ discontinued-approach climb gradients when OEI in approach configuration at landing weight and given environmental conditions (EASA, 2007; FAA, 2011). The landing climb of $3.2 \%$ is operationally required (EASA, 2007; FAA, 2011, 2013; JAA, 2007) only with AEO TOGA thrust for airplane in landing configuration at MSLW (and below).

As the last test, the performance computations for a 350,000 lb HBPR-equipped airplane cruising at FL360 ISA with conditions at $-56.3{ }^{\circ} \mathrm{C}$ air was considered, and results are presented in Figure 8 . About $22,068 \mathrm{lbs}(9,816 \mathrm{daN}$ or $98.16 \mathrm{kN})$ of thrust is required at TAS of 480 knots $(890$ $\mathrm{km} / \mathrm{hr}), M=0.836$, and 262 knots CAS/EAS respectively. Computed TSFC (Figure 3) is about $0.56428 \mathrm{lb} / \mathrm{hr} / \mathrm{lb}$ (or $\mathrm{kg} / \mathrm{hr} / \mathrm{daN}$ ) and fuel flow is $6,226 \mathrm{lb} / \mathrm{hr}(2,830 \mathrm{~kg} / \mathrm{hr}$ ) per engine. This fictional subsonic $T$-category airplane has

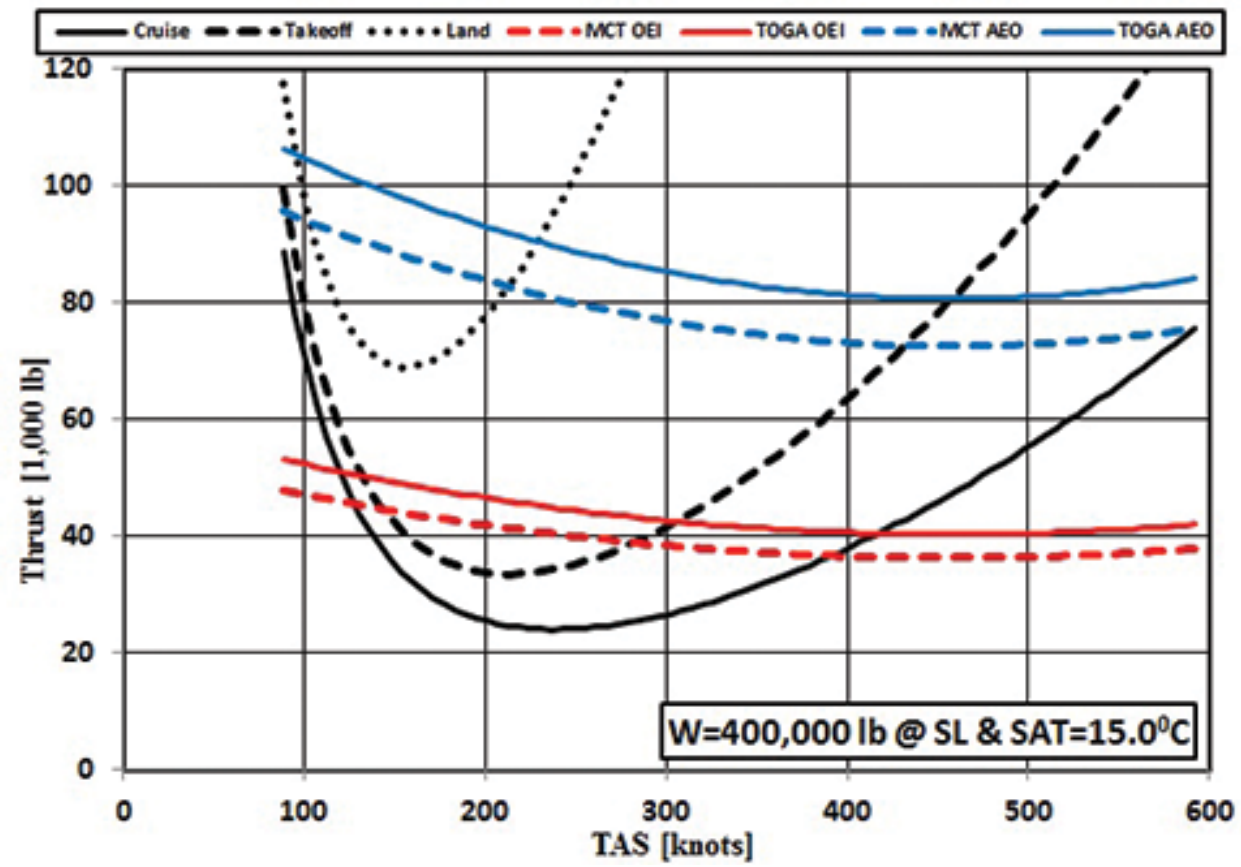

Figure 4. Pénaud diagram for HBPR turbofan thrust available and thrust required for AEO and OEI cases at MSTOW and SL ISA. 


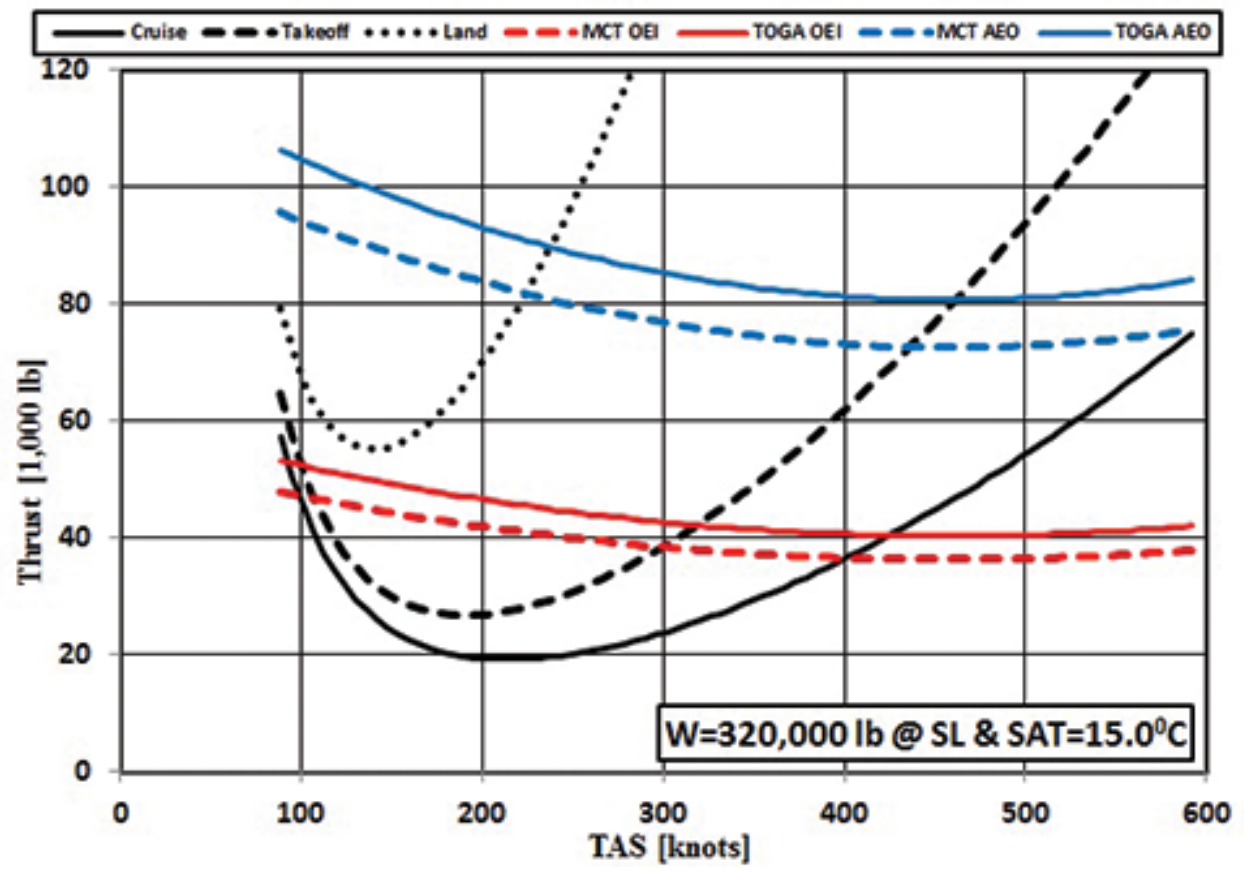

Figure 5. Pénaud diagram for HBPR turbofan thrust available and thrust required for AEO and OEI cases at MSLW and SL ISA.

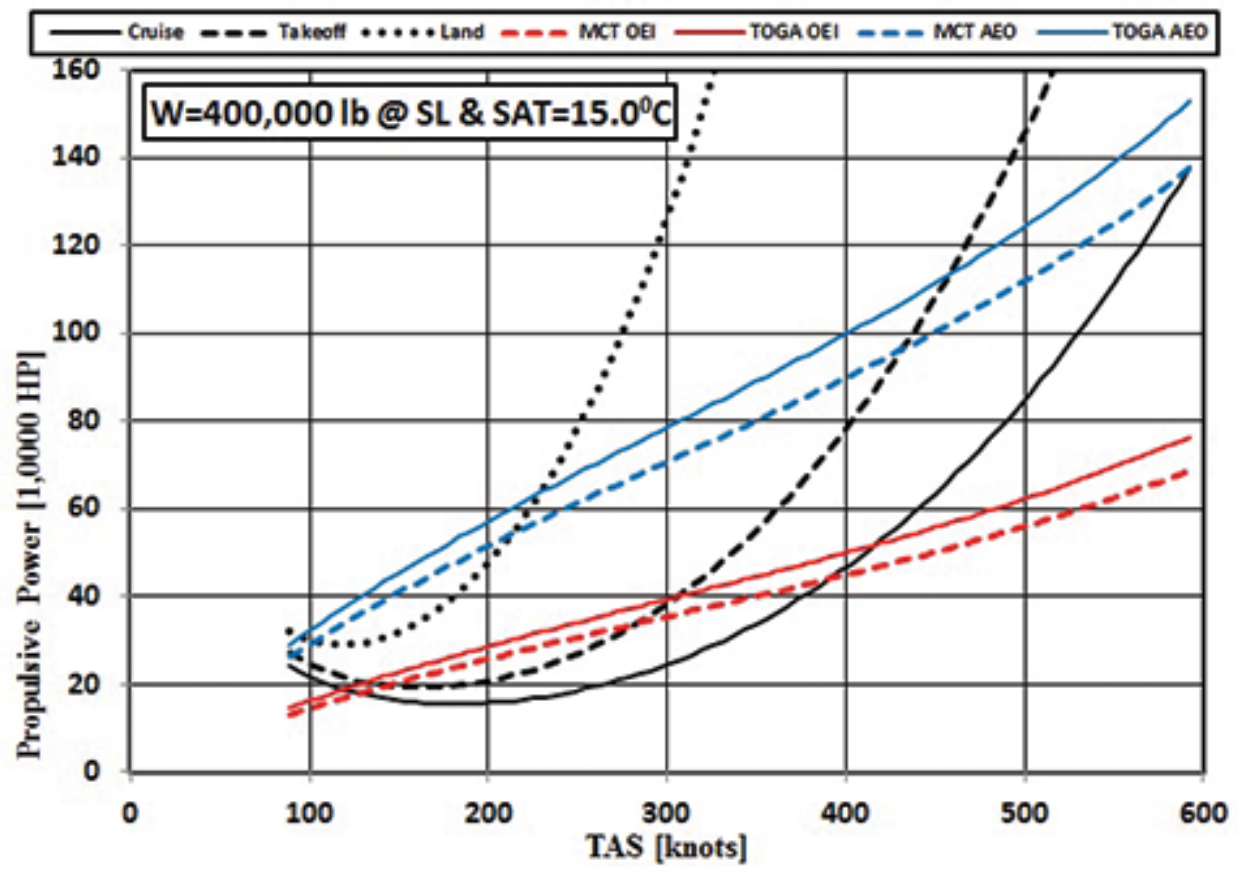

Figure 6. Pénaud diagram for HBPR turbofan power available and power required in AEO and OEI cases at MSTOW and SL ISA.

$M_{C R}=0.765, M_{M O}=0.860$, and $M_{D D}=0.872$. Maximum fuel capacity is $162,000 \mathrm{lbs}$, and the instantaneous $S A R=R F / W=v /(T S F C \times D)$ at $350,000 \mathrm{lbs}$ is about $38.55 \mathrm{NM} /(1,000 \mathrm{lbs}$ of fuel $)$. The maximum still-air range is then about 6,000 NM while meeting regulatory fuel reserve requirements (Daidzic, 2014b). The EOW (Empty
Operating Weight) is 190,000 lbs and MZFW (Maximum Zero-Fuel Weight) is 280,000 lbs. Maximum payload is 90,000 lbs, which would imply carrying 300 average passengers and 30,000 lbs of cargo. Clearly, the airplane would not be able to maintain cruise at FL360 during OEI condition. It would have to drift down to, say, FL240 


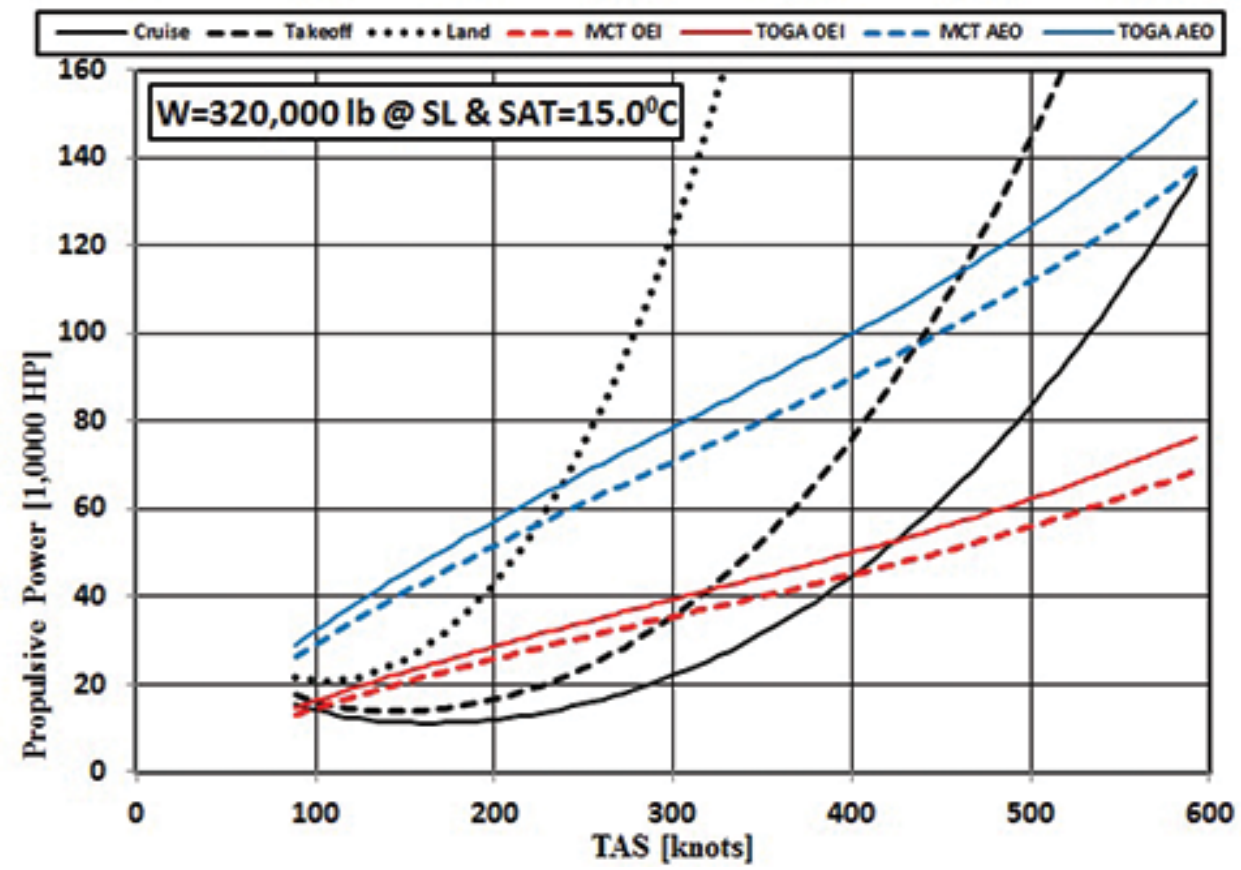

Figure 7. Pénaud diagram for HBPR turbofan power available and power required in AEO and OEI cases at MSLW and SL ISA.

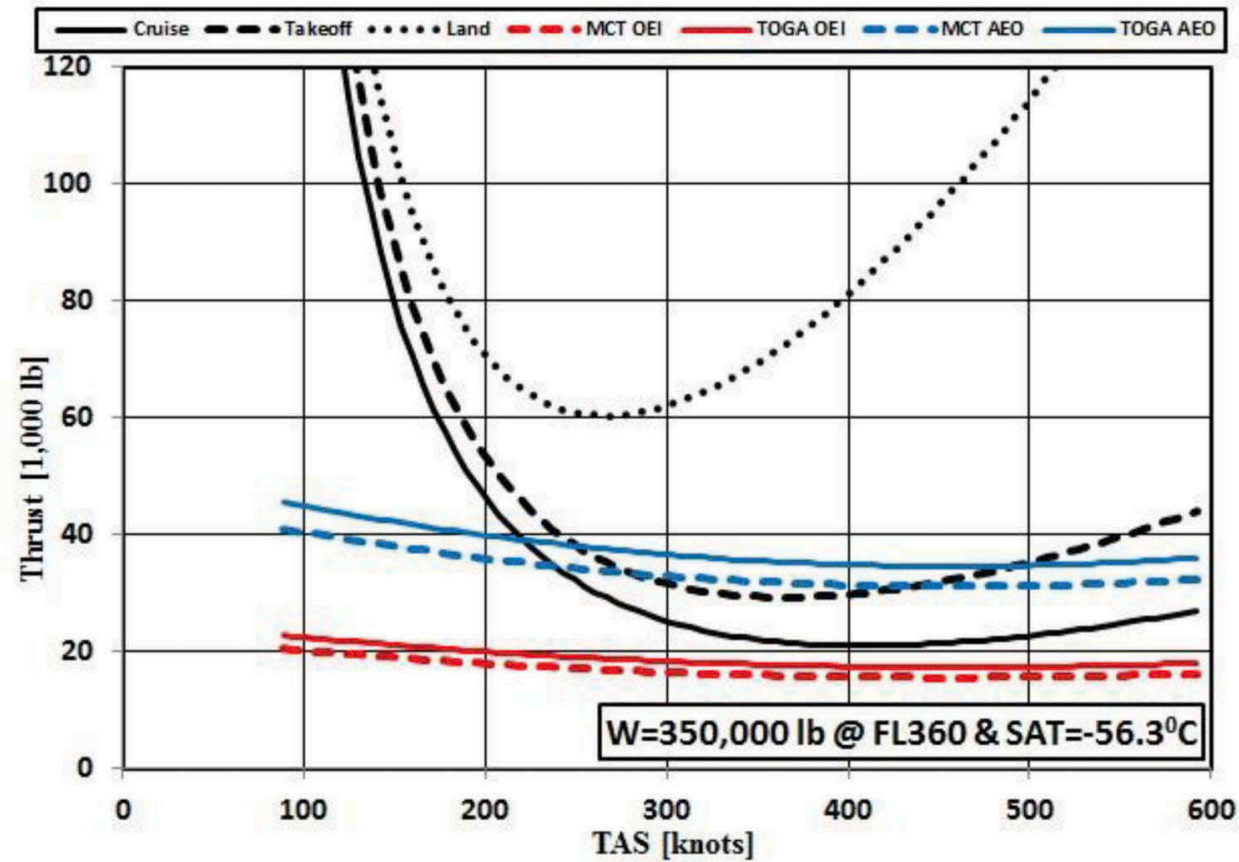

Figure 8. Pénaud diagram for high-altitude cruise HBPR turbofan thrust available and required for AEO and OEI cases. Steep rise in compressible drag coefficient would commence above at about 490 KTAS.

and slow down to 367 KTAS (250 KCAS/KEAS) or $M=0.608$, requiring about $21,536 \mathrm{lbs}$ of thrust $\left(<\right.$ MCT OEI @ FL240=21,605 lb@-32.5 $\left.{ }^{\circ} \mathrm{C}\right)$ from the remaining working engine. Drag curves for takeoff and landing configuration are plotted for reference only, but have no use in cruise flight. Besides, specific $V_{F E}$ 's would limit the use of flaps at high dynamic pressures. High-speed limitation
$\left(V_{M O} / M_{M O}\right)$ for the fictional FAR/CS 25 T-category airplane used is $350 / 0.86$.

\section{Results and Discussion}

Now that the accuracy and the reliability of the numerical algorithm and performance (thrust and power 
required and available) calculations have been thoroughly and satisfactorily tested, we can turn toward the actual estimate of performance airframe-powerplant airspeeds for a fictitious T-category airplane. Simplistic, speed-independent thrust, assumptions frequently made in the literature, leads to $V_{X}=V_{E}=V_{M D}$ in pure turbojet-type airplanes for both AEO and OEI cases, which is quite unrealistic and inaccurate for real airplanes and modern turbofan engines. The problem is of course that numerical methods must be applied to solve nonlinear equations, which by no means is simple task.

\section{Estimation of Aircraft Performance Airspeeds}

An extremely large number of computations of critical control and performance airspeeds have been conducted for in-flight weights ranging from 300,000 to $400,000 \mathrm{lbs}$ in $10,000 \mathrm{lb}$ increments. The computations have been repeated for various altitudes, pressures, and temperatures and then always for both OEI and AEO conditions. For each computation a numerical NR/MNR converging iterative solution of an appropriate nonlinear equation has been performed.

The results of $V_{X} / V_{S}$ ratio for the AEO/OEI condition and for an airplane in takeoff configuration with TOGA thrust at SL ISA are shown in Figure 9. Additionally, the weightindependent $V_{M D} / V_{S}$ and the $V_{3} / V_{S}$ airspeed ratios are shown. Interestingly, the $V_{M D} / V_{S}$ ratio is quite high (1.622) in takeoff configuration. We have defined $V_{3}$ here as $V_{2 M I N}+20$ knots. Such airspeed is typically attained during AEO takeoffs at screen height (SH) and possibly during OEI overspeed (improved-climb) takeoffs (Daidzic, 2014a).

The AEO and OEI $V_{X} / V_{S}$ ratio along other speed ratios at FL50 ISA is shown in Figure 10. This condition simulates departure and climb from a higher elevation airport (e.g., Denver, CO) The AEO and OEI $V_{X} / V_{S}$ ratios increase slightly with altitude (decreasing temperature). Also the $V x$ airspeed increases absolutely with altitude, both in TAS and CAS/EAS sense. Some really bad news is that $V_{X, O E I}$ is markedly higher than $V_{X, A E O}$. Just when a crippled airplane, devastated by a loss of one engine, needs regulatory required climb gradient, it also needs to accelerate to higher airspeeds, but with only half thrust available. Indeed, severe payload penalties must be paid occasionally to make sure an airplane can overfly obstacles by $35 \mathrm{ft}$ vertically along a net flight path during OEI condition. The $V_{M D} / V_{S}$ ratio does not change with altitude or weight and certainly not with the AEO/OEI condition.

It is important to emphasize again that FAR/CS 25 T-category airplanes normally do not climb initially at $V x$, which is a quite faster airspeed than (OEI) takeoff safety speeds $V_{2}$ (typically in the range $V_{2 M I N}$ to $V_{2 M I N}+20$ ). Minimum takeoff safety speed is about $20 \%$ above stalling speed in this given configuration. The main reason that $V_{X}$ is almost never used is that the difference between $V_{X}$ and $V_{2}$ can easily exceed 50 knots (Daidzic, 2014a). Gaining altitude after takeoff is far more important than accelerating to faster airspeeds (e.g., during $2^{\text {nd }}$-segment climb). However, if the declared field lengths (TODA, TORA) allow, it is possible to perform overspeed- or improvedclimb takeoff (Daidzic, 20014a; Swatton, 2008), increasing rotation, lift-off, and SH- airspeeds (say $V_{2}+20$ ) when OEI noticeably reduces aerodynamic drag, enabling steeper climb gradients (Daidzic, 2014a) and facilitating obstacle clearance and increased payload.

The airspeed ratios for airplanes at different weights with SL ISA MCT in (clean) cruise configuration are

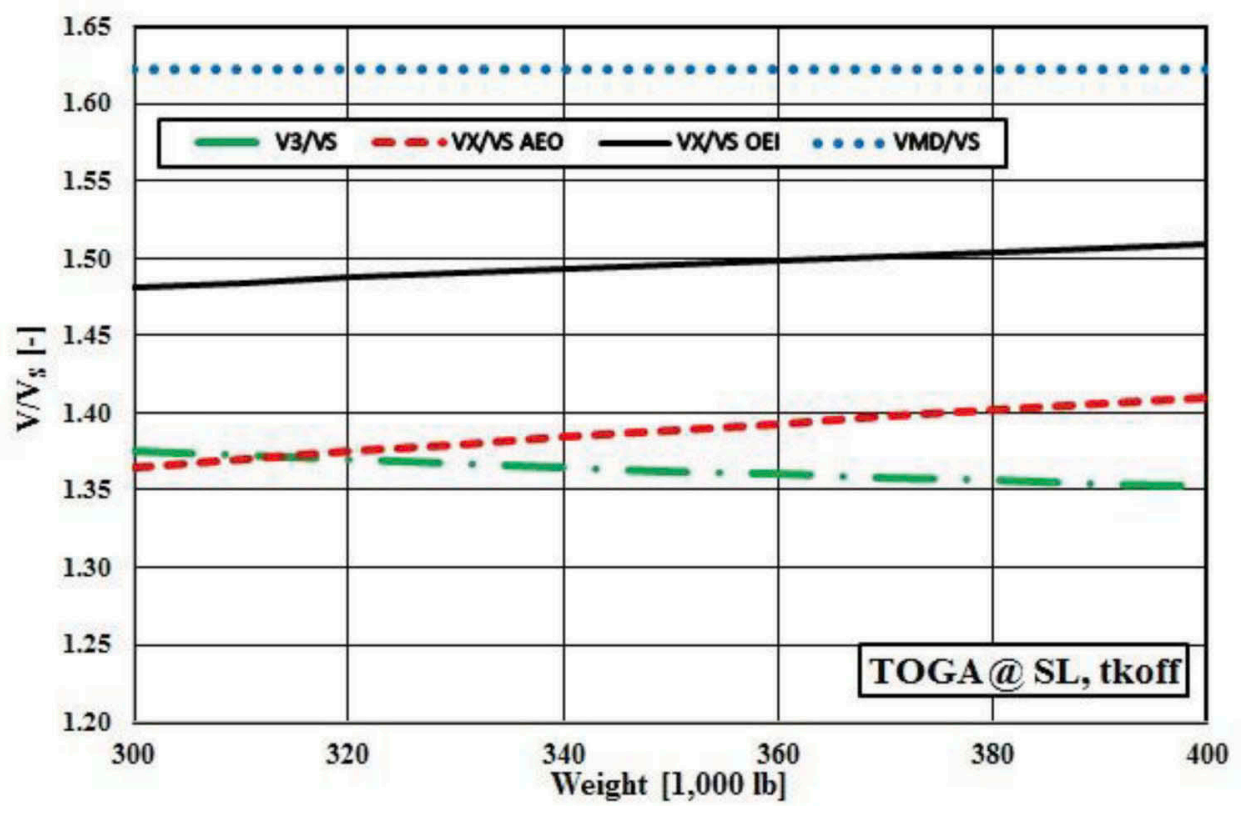

Figure 9. HBPR turbofan speed ratios as function of TOW for takeoff configuration, AEO and OEI TOGA thrust, and SL ISA. 


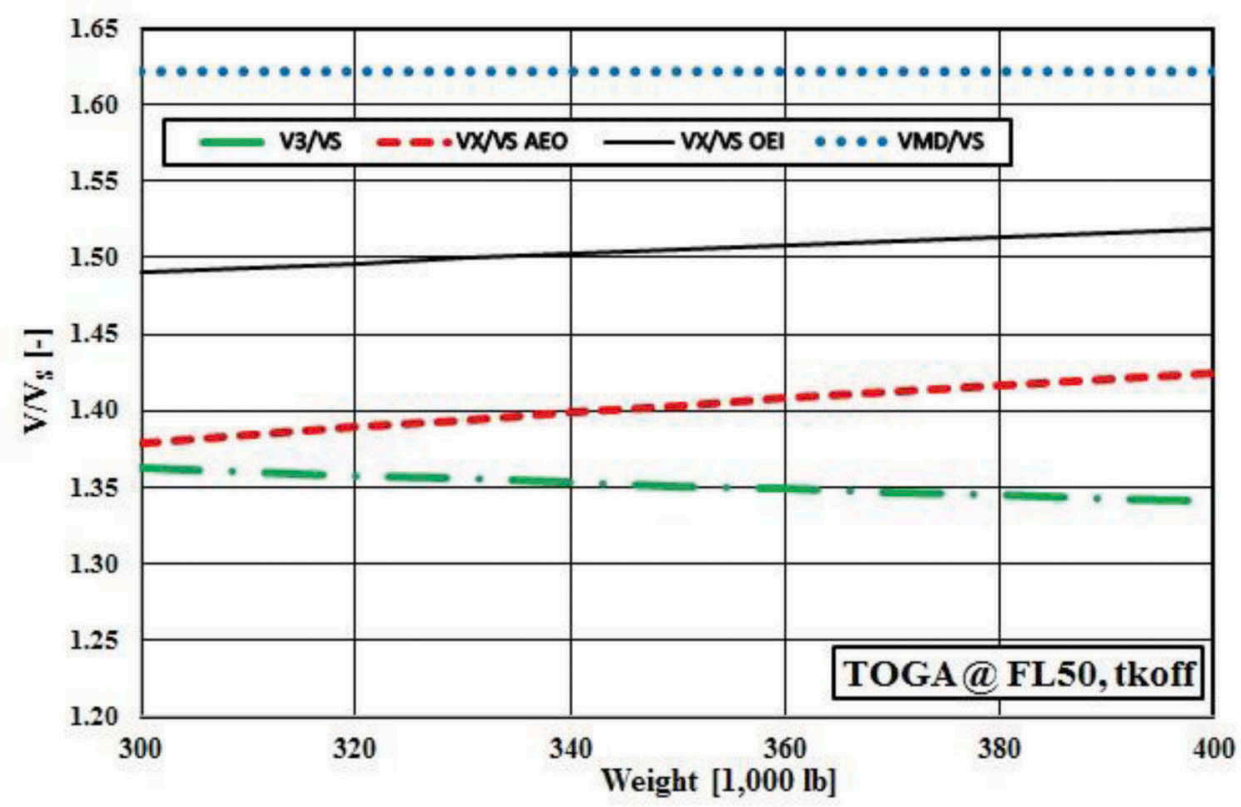

Figure 10. HBPR turbofan speed ratios as function of takeoff weight (TOW) for takeoff configuration, AEO and OEI TOGA thrust, and FL50 ISA.

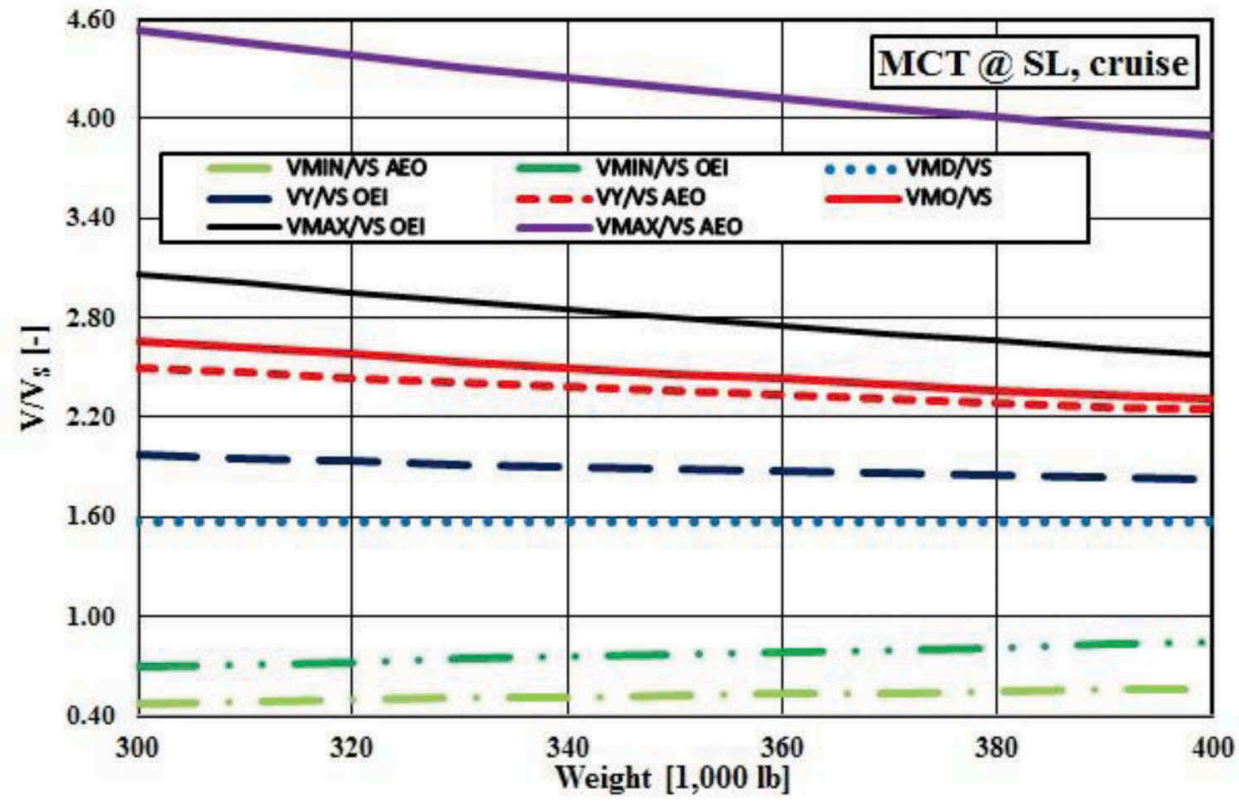

Figure 11. HBPR turbofan speed ratios as a function of TOW for cruise configuration at MCT and SL ISA.

presented in Figure 11. Clearly, the minimum propulsionlimit airspeeds are not attainable. Also the maximum airspeeds (AEO or OEI) would not be prohibited due to max-Q or dynamic pressure limit (about $20 \mathrm{kPa}$ or $2.9 \mathrm{psi}$ and expressed through an airframe-dependent $V_{M O}$ of 350 knots in this case). They are also unrealistic because no wave drag was included. The $V_{Y} / V_{S}$ for AEO SL cruise is very close to the max-Q limit and also decreases with weight. Unlike the steepest-climb $V_{X}$ airspeeds, the AEO $V_{Y} / V_{S}$ is larger than OEI $V_{Y} / V_{S}$. A modern T-category airplane will cruise-climb at relatively high CAS/M airspeeds (e.g., 320/0.78), which closely approximates maximum-rate $V_{Y}$ climb. Climb at constant CAS/EAS will result in actual acceleration in terms of TAS due to air density decrease (Padilla, 1996). Important airspeed ratios for airplanes cruising at MCT and FL50 are shown in Figure 12. The minimum propulsion-limit airspeeds are no longer depicted as they are always below stalling airspeeds. Similarly, the maximum propulsion-limit airspeeds (AEO or OEI) are higher than the max-Q airspeed 


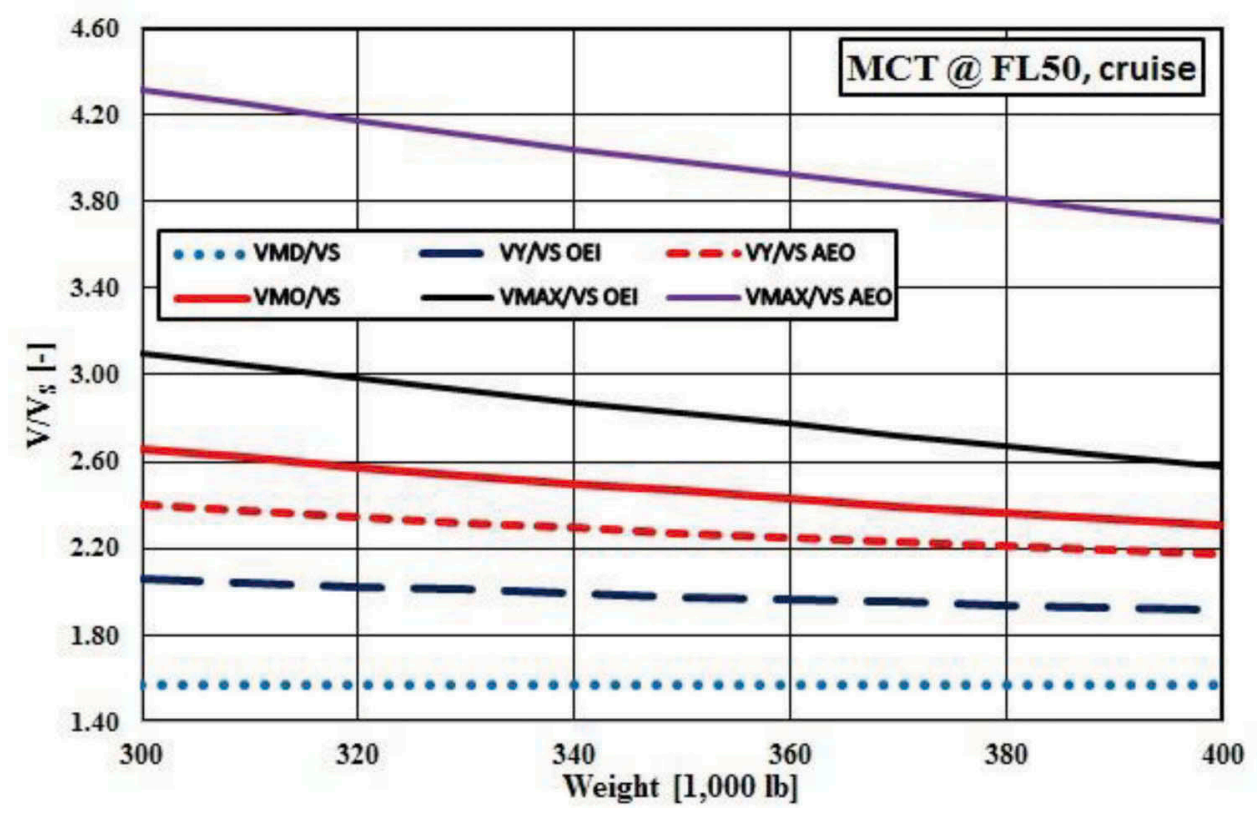

Figure 12. HBPR turbofan speed ratios as a function of TOW for cruise configuration at MCT and FL50 ISA.

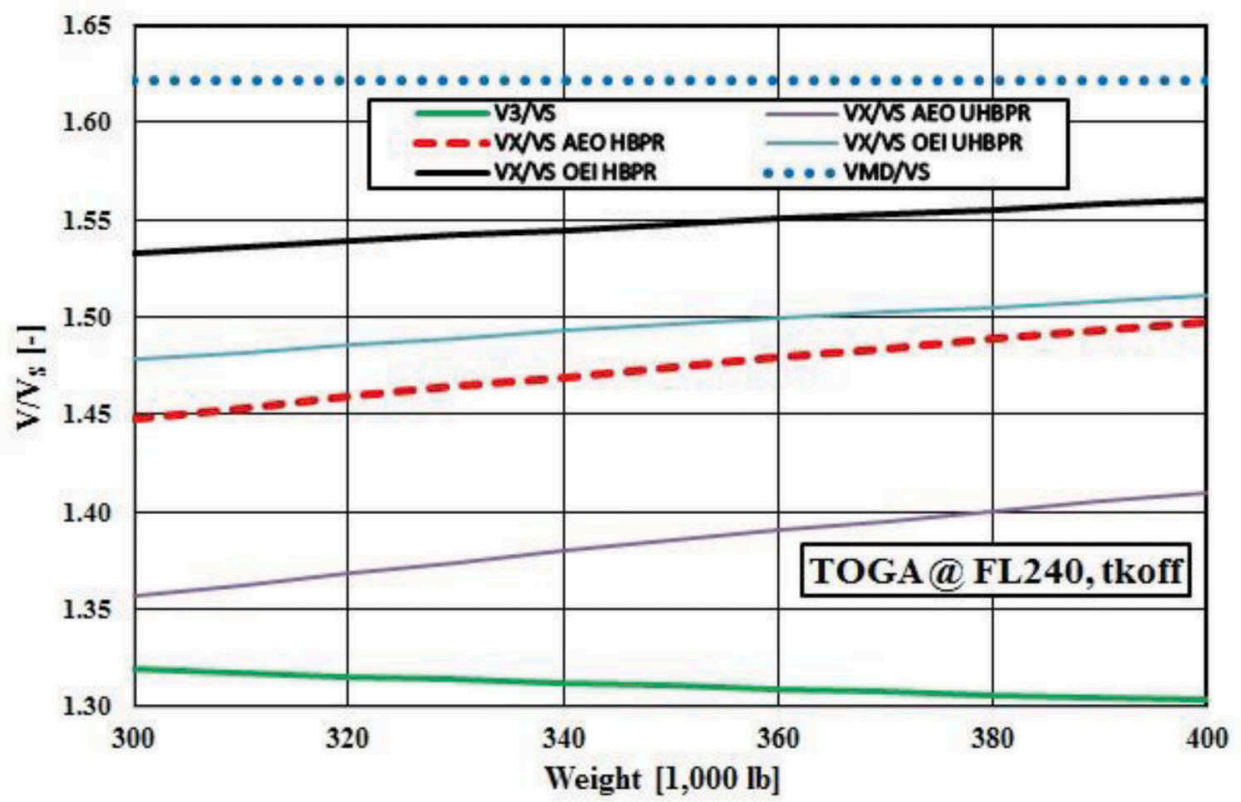

Figure 13. AEO and OEI $V_{X} / V_{S}$ ratios as a function of TOW in takeoff configuration and TOGA thrust at FL 240 ISA for HBPR and UHBPR turbofans.

and thus prohibited. The AEO $V_{Y} / V_{S}$ is again faster than OEI $V_{Y} / V_{S}$, and both ratios decrease with weight, although both CAS/EAS $V_{S}$ and $V_{Y}$ must increase with weight. In terms of CAS or EAS, the $V_{Y} / V_{S}$ is again very close to the max-Q limit and decreases with altitude. Although, in the real world, SL or FL50 cruise is far too low to fly at high airspeed (maximum 250 KCAS below FL100), it is used solely to be consistent in data presentation while showing altitude dependence.

\section{The Effect of BPR on Aircraft Performance Airspeeds}

The trend in modern turbofan designs is to move toward ever higher BPR. One of the main reasons for that is the further reduction of TSFC and noise levels. Although, to the best of our knowledge no successful general theory exists that relates BPR to speed-dependent thrust, increasing BPR will usually increase $a_{1}$ (and $b_{1}$ ) and reduce $a_{2}$ (and $b_{2}$ ) coefficients in a general thrust-available equation 
(Equations 8 and 9). Two turbofan engines are considered here. The first is a contemporary HBPR turbofan (BPR 5:1) and was used in all previous computations, and the second is the UHBPR turbofan (say, BPR is 10:1). All the critical HBPR and UHBPR powerplant data is summarized in Table 2. Higher BPR means less air directed through the engine core (gas generator), which now has to extract even more energy to power an ever larger fan (Mattingly, 2005; Treager, 1996). It is thus logical to assume that overall ram effect will simultaneously decrease. It is also assumed that UHBPR and HBPR engines used here are of similar weight and installed drag.

The resulting performance airspeed ratios for an airplane cruising at FL240 in ISA troposphere are shown in Figure 13. It is impossible to find a condition for which all different airspeeds would realistically coexist in the same airplane configuration and thrust rating. The $V_{X}$ speed is possibly (but rarely) only used in initial takeoff climb and obstacle clearance with TOGA thrust and lower altitudes. On the other hand maximum-rate climbs are used in the later climb phases (above 10,000 ft) at MCT and in clean airplane configuration. Maximum propulsion-limited cruising airspeed at high flight levels is mostly unattainable due to $M_{M O}$ limitation. Squeezing all these airspeeds (and ratios) with different thrust ratings and airframe configurations in one diagram does not do any justice to realistic airplane operations, but is presented here regardless for comparison and space constraints. Cruising altitude of FL240 was chosen, as both AEO and OEI level flights are still possible.

Clearly, the minimum-drag and the power-off stalling airspeed do not change with the choice of powerplant, provided installed drag and weight of new powerplant is not much different from the original one. As expected, a UHBPR turbofan will result in noticeably slower AEO and OEI $V_{X}$ speeds. Combined with the higher static thrust, the climbing speed is slower while the climb gradient (not shown here) is higher. Both of these facts significantly improve safety of operations. Takeoff configuration assumes proper high-lift devices deployed and gears retracted.

The last results shown here are for $V_{Y} / V_{S}$ and $V_{M A X} / V_{S}$ ratios at FL240 for HBPR and UHBPR powerplants in clean configuration and for AEO and OEI cases. Results are shown in Figures 14 and 15. As expected, $V_{Y}$ airspeeds are faster than $V_{M D}$ airspeeds. Maximum rate of climb airspeeds almost reaches $V_{M O}$ at higher weights. A UHBPR turbofan will achieve fastest climbs at airspeeds significantly slower than in common existing HBPR turbofans. This is not all that great of news as it will slow down forward motion.

Maximum propulsion-limited airspeeds are faster than $V_{M O} / M_{M O}$ and thus never achieved in flight. The result is also unrealistic since the wave drag was not incorporated. The curves for OEI $V_{M A X} / V_{S}$ ratios for HBPR and UHBPR stop at weights of 360,000 and 390,000 lbs respectively (Figure 15), simply because higher airspeeds cannot be attained at ISA FL240 at higher weights. In fact, the numerical algorithm only returned complex-conjugate roots. The maximum propulsion-limited airspeeds are unrealistically high, as seen in Figures 15.

By including the coefficient of wave drag, the maximum-propulsion airspeeds will come down significantly as is the case in real airplanes. However, this effort will be conducted and demonstrated in a separate publication.

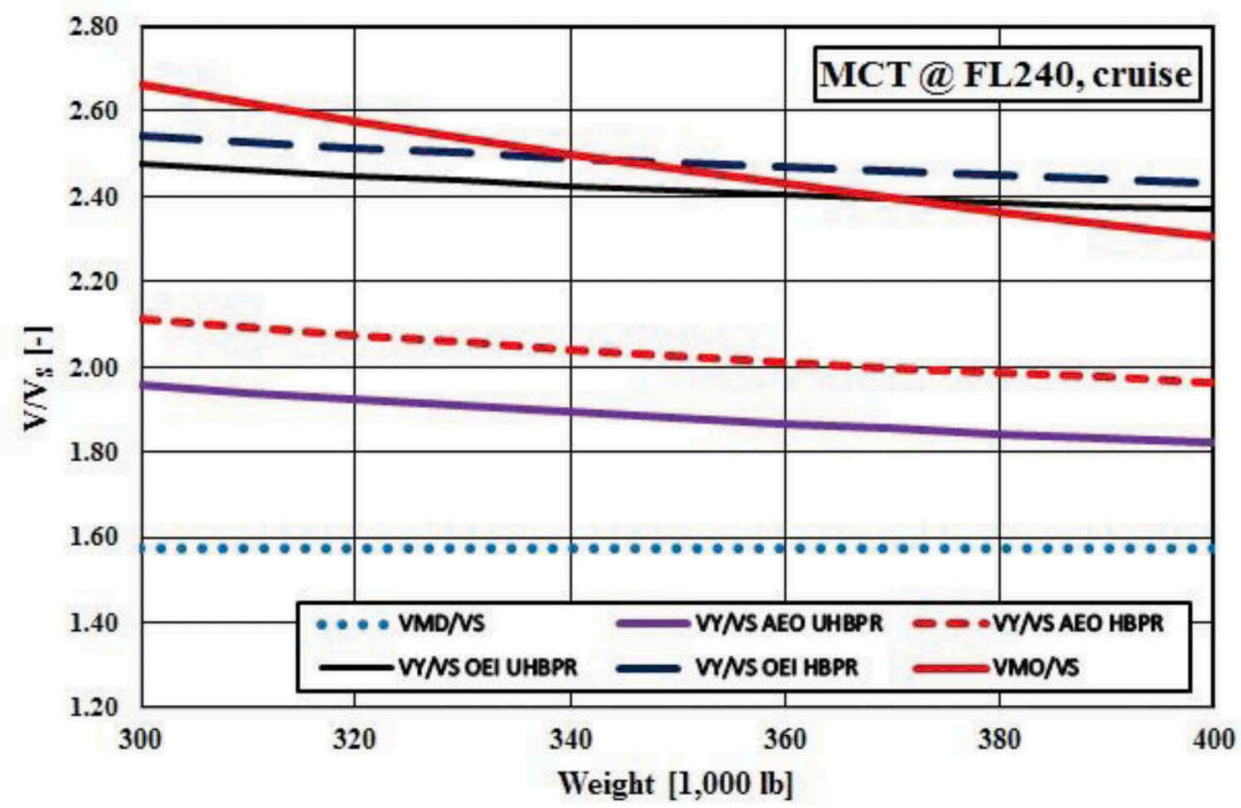

Figure 14. AEO and OEI $V_{Y} / V_{S}$ as a function of TOW in cruise at FL 240 ISA for HBPR and UHBPR turbofans. 


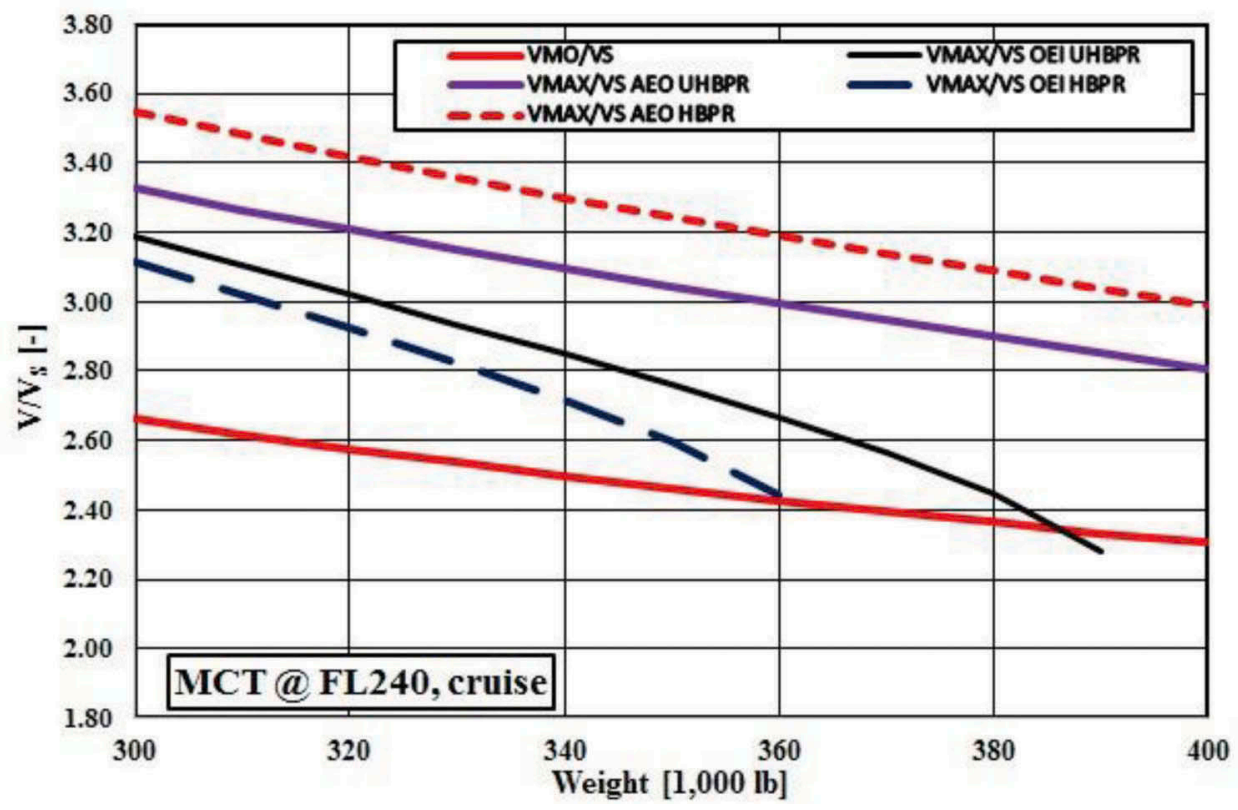

Figure 15. AEO and OEI $V_{M A X} / V_{S}$ as a function of TOW in cruise at FL 240 ISA for HBPR and UHBPR turbofans.

The final airplane drag figures are extracted from the wind-tunnel scale models and prototype(s) flight measurements. The procedure described here still remains very useful. Piecewise continuous polynomials obtained by data fitting (e.g., least-square-root approximation) for the entire or several non-overlapping airspeed ranges can be used instead of the conventional theoretical drag polar. The same can be done with the experimentally estimated, installed, and/or uninstalled thrust data. Having all experimental data in the form of least-square approximating polynomials, the performance speeds can be easily evaluated using the numerical procedure described earlier. Moreover, the polynomials could be of different (and higher) order and also be noninteger, which will only affect NR expressions, but otherwise nothing significant changes. Although there was no intention to simulate any particular aircraft performance, the figures obtained are not very different from those for Boeing 767-300 ER and common turbofan engines used to power it. Since the basic weight and aerodynamic data are similar, the airspeeds estimated here are not very different from certified data for B767 (Boeing, 2005).

Future work will incorporate transonic wave drag and its effect on the maximum-propulsion and drag-divergence airspeeds and Mach numbers. Maximum ranges will be estimated for several distinct cases: flight at constant AOA $\left(C_{L}\right)$, constant altitude, and constant airspeed. Particularly, we are interested in the evaluation of the maximum propulsion-limited constant-altitude cruising airspeed in the presence of wave drag. Although, engines may still provide enough thrust to exceed $M_{M O}$ at cruising altitudes, the margin by which that is being accomplished will be significantly reduced past $M_{D D}$ due to steep drag rise. The order of drag polynomials may be higher than $4^{\text {th }}$ as already seen from Hilton's (1952) expression for wave drag. Such cases will be easily dealt with using the presented numerical method. Any non-integer exponents and approximated experimental drag data can be incorporated. Wind-tunnel scale models and flight test drag data can be approximated using polynomial representation for the entire flight envelope (and beyond), and the methods described here can be easily implemented.

\section{Conclusions}

A numerical method to calculate turbofan-powered airplane performance airspeeds is presented. The resulting equations describing steady-state flight regime including drag and trust in general polynomial form cannot be solved analytically. A general speed- and altitude-dependent polynomial thrust generation is assumed. ISA atmosphere was used for performance computations. Drag is modeled using the familiar parabolic polar. Wave drag was not modeled, although considerations of its influence on maximumpropulsion and cruising airspeeds were discussed. A new speed- and altitude-dependent fuel law that covers the entire turbofan engine operating envelope was proposed. A consistent and systematic derivation of control and performance airspeeds was described. The numerical method of finding real positive zeroes of polynomials, which represent optimal airspeeds, is based on the regular or modified Newton-Raphson methods. Negative real and complexconjugate roots were naturally discarded on physical grounds. All implemented numerical methods for seeking real roots, with possible multiplicity, of nonlinear functions were also verified against the explicit analytical solutions when available. Methods utilizing global and complex root-finding 
subroutines written in-house and, additionally, by using professional commercial software and numerical libraries were utilized. Analysis of the performance speeds for AEO and OEI cases at different weights and altitudes revealed that generally $V x, V_{E}, V y, V_{M R C}$, and $V_{M A X}$ decrease with increasing BPR. On the other hand, minimum-drag and power-off stall airspeeds are only airframe dependent and thus totally insensitive to powerplant characteristics. Theoretical minimum-power and maximum cruise range airspeeds with constant speed-independent fuel consumption are solely airframe dependent as well. The ratios of performance speeds to stalling speeds demonstrated important changes with altitude and weight for both AEO and OEI cases with both HBPR and UHBPR engines. The analytical-numerical method presented here can be used to optimize many special takeoff operations, such as overspeed takeoffs, with and without derated/reduced thrust and for arbitrary close- and distant-obstacle geometry. Calculation of maximum-range airspeeds for various flight conditions and based on the similar speed-dependent thrust relationships will be reported in a subsequent article. Last but not least, the proposed numerical method can be used for any arbitrary drag polar polynomial, including actual measured drag characteristic in wind tunnels and/or flight tests. Turbofan characteristics could also be represented in a suitable polynomial form and solved using described nonlinear equation solvers. This method provides a powerful tool in estimation of critical control and performance airspeeds in conceptual and early airplane design phases and helps in early development of best practices and flight techniques. Design optimizations can also be performed using various cost functions.

\section{References}

Anderson, J. D. Jr. (1999). Aircraft performance and design. New York: McGraw-Hill.

Ashley, H. (1992). Engineering analysis of flight vehicles. Mineola, NY: Dover.

Ashley, H, \& Landahl, M. (1985). Aerodynamics of wings and bodies. Mineola, NY: Dover.

Asselin, M. (1997). An introduction to aircraft performance. Reston, VA: American Institute for Aeronautics and Astronautics (AIAA). http://dx. doi.org/10.2514/4.861529

Bertin, J. J, \& Cummings, R. M. (2009). Aerodynamics for engineers (5th ed.). Upper Saddle River, NJ: Pearson Prentice Hall.

Boeing Commercial Airplanes. (2005). 767 Airplane characteristics for airport planning (D6-58328). Seattle, WA.

Carnahan, B, Luther, H. A, \& Wilkes, J. O. (1969). Applied Numerical Methods, New York: John Wiley \& Sons.

Cavalcanti, S, \& Papini, M. (2004). Preliminary model matching of the EMBRAER 170 jet. Journal of Aircraft, 41(4), 703-710. http://dx.doi. org/10.2514/1.3207

Cavcar, M, \& Cavcar, A. (2004). Approximate solutions of range for constant altitude - constant high subsonic speed flight of transport aircraft. Aerospace Science and Technology, 8(6), 557-567. http://dx. doi.org/10.1016/j.ast.2004.04.002

Cavcar, M, \& Cavcar, A. (2005). Optimum range and endurance of piston propeller aircraft with cambered wing. Journal of Aircraft, 42(1), 212 217. http://dx.doi.org/10.2514/1.6095
Chapra, S. C, \& Canale, R. P. (2006). Numerical methods for engineers (5th ed.). Boston: McGraw-Hill.

Conte, S. C, \& de Boor C. (1986). Elementary numerical analysis: An algorithmic approach, (3rd int. ed.). Singapore: McGraw-Hill.

Daidzic, N. E. (2012, September). Jet engine thrust ratings. Professional Pilot, 46(9), 92-96.

Daidzic, N. E. (2013, November). Aircraft tests arrive at numbers pilots need for safe operations. Professional Pilot, 47(11), 100-104.

Daidzic, N. E. (2014a). A total-energy based model of airplane overspeed takeoffs. International Journal of Aviation, Aeronautics, and Aerospace, 1(3), 1-25.

Daidzic, N. E. (2014b). Achieving global range in future subsonic and supersonic airplanes. International Journal of Aviation, Aeronautics, and Aerospace, 1(4), 1-29.

Daidzic, N. E. (2015). Efficient general computational method for estimation of standard atmosphere parameters. International Journal of Aviation, Aeronautics, and Aerospace, 2(1), 1-32.

Daidzic, N. E, \& Shrestha, J. (2008). Airplane landing performance on contaminated runways in adverse conditions. Journal of Aircraft, 45(6), 2131-2144. http://dx.doi.org/10.2514/1.38056

Demidovich, B. P, \& Maron, I. A. (1987). Computational mathematics. Moscow: MIR Publishers.

Eshelby, M. E. (2000). Aircraft performance: Theory and practice. Boston: Elsevier. http://dx.doi.org/10.2514/4.473982

European Aviation Safety Agency (EASA). (2007). Certification specifications for large aeroplanes (CS-25, Amendment 3, 19 September 2007). Cologne, Germany.

Euston, M, Coote, P, Mahony, R, Kim, J, \& Hamel, T. (2008). A complementary filter for attitude estimation of a fixed-wing UAV. Intelligent Robots and Systems, 2008. IROS 2008. IEEE/RSJ International Conference on Intelligent Robots and Systems, 340345. http://dx.doi.org/10.1109/iros.2008.4650766

Federal Aviation Administration (FAA). (2011). Flight test guide for certification of transport category airplanes (AC 25-7B). Washington, DC.

Federal Aviation Administration (FAA). (2013). Airworthiness standards: Transport category airplanes (Subpart B Title 14, CFR Part 25). Washington, DC.

Filippone, A. (2006). Flight performance of fixed and rotary wing aircraft. Reston, VA: American Institute for Aeronautics and Astronautics (AIAA). http://dx.doi.org/10.2514/4.478390

Filippone, A. (2012). Advanced aircraft flight performance. Cambridge: Cambridge University Press. http://dx.doi.org/10.1017/CBO9781139161893

Fujino, M, \& Kawamura, K. (2003). Wave-drag characteristics of an overthe-wing nacelle business-jet configuration. Journal of Aircraft. 40(6), 1177-1184. http://dx.doi.org/10.2514/2.7207

Ghenaiet, A. (2007). Determination of minimum thrust requirement for a passenger aircraft. Journal of Aircraft, 44(6), 1787-1792. http://dx.doi. org/ 10.2514/1.27990

Hale, F. J. (1984). Introduction to aircraft performance, selection, and design. New York: John Wiley \& Sons.

Hilton, W. F. (1952). High speed aerodynamics. London: Longmans \& Co.

Isikveren, A. T. (2002). Identifying economically optimal flight techniques. Journal of Aircraft. 39, 528-544. http://dx.doi.org/10. $2514 / 2.2982$

Jakirlić, S, Eisfeld, B, Jester-Zuerker, R, \& Kroll, N. (2007). Near-wall, Reynolds-stress model calculations of transonic flow configurations relevant to aircraft aerodynamics. International Journal of Heat and Fluid Flow, 28(4), 602-615. http://dx.doi.org/10.1016/j.ijheatfluidflow. 2007.04.001

Jaw, C. L, \& Mattingly, J. D. (2009). Aircraft engine controls: Design, system analysis, and health monitoring. Reston, VA: American Institute for Aeronautics and Astronautics. http://dx.doi.org/10.2514/ 4.867057 
Joint Aviation Authorities (JAA). (2007). JAR-OPS 1: Commercial air transportation (Aeroplanes), (Amendment 13, 1 May 2007). Hoofddorp, Netherlands.

Lie, F.. A. P, \& Gebre-Egziabher, D. (2013). Synthetic air data systems. Journal of Aircraft, 50(4), 1234-1249. http://dx.doi.org/ 10.2514/ $1 . \mathrm{C} 032177$

Liepmann, H. W, \& Roshko A. (2001). Elements of gasdynamics. Mineola, NY: Dover.

MacIsaac, B, \& Langton, R. (2011). Gas turbine propulsion systems. ChichesterUK: John Wiley \& Sons. http://dx.doi.org/10.2514/4. 868467

Mair, W. A, \& Birdsall, D. L. (1992). Aircraft performance. Cambridge: Cambridge University Press. http://dx.doi.org/10.1017/CBO9780511607134

Malone, B, \& Mason, W. H. (1995). Multidisciplinary optimization in aircraft design using analytic technology models. Journal of Aircraft, 32(2), 431-437. http://dx.doi.org/10.2514/3.46734

Mason, W. H. (1995). On the use of the potential flow model for aerodynamic design at transonic speeds (AIAA 95-0741). 33rd Aerospace Sciences Meeting \& Exhibit. Reno, NV. http://dx.doi.org/ 10.2514/6.1995-741

Mason, W. H. (2002, April 4). Transonic aerodynamics of airfoils and wings [AOE 4124 Configuration Aerodynamics Lecture Notes], Virginia Polytechnic Institute and State University. Retrieved from http://www.aoe.vt.edu/ mason/Mason_f/ConfigAeroTran-sonics.pdf.

Mattingly, J. D. (2005). Elements of gas turbine propulsion. Reston, VA: American Institute for Aeronautics and Astronautics.

McCormick, B. W. (1995). Aerodynamics, aeronautics and flight mechanics (2nd ed.), . New York: John Wiley \& Sons.

Menon, P.. K. A. (1989). Study of aircraft cruise. Journal of Guidance, Control, and Dynamics, 12(5), 631-639. http://dx.doi.org/10.2514/ 3.20456

Miller, L. E. (1993). Optimal cruise performance. Journal of Aircraft, 30(3), 403-405. http://dx.doi.org/10.2514/3.46349

Nicolai, L. M, \& Carichner, G. E. (2010). Fundamentals of aircraft and airship design: Volume I-aircraft design. Reston, VA: American Institute for Aeronautics and Astronautics. http://dx.doi.org/10.2514/4. 867538

Ojha, S. K. (1995). Flight performance of aircraft. Washington, DC: American Institute for Aeronautics and Astronautics. http://dx.doi.org/ $10.2514 / 4.861826$

Padilla, C. E. (1996). Optimizing jet transport efficiency: Performance, operations, and economics. New York: McGraw-Hill.
Phillips, W. F. (2004). Mechanics of flight. New York: John Wiley \& Sons.

Press, W. H, Teulkolsky, S. A, Vetterling, W. T, \& Flannery, B. P. (1992). Numerical recipes in FORTRAN: The art of scientific computing (2nd ed.). Cambridge: Cambridge University Press.

Ralston, A, \& Rabinowitz, P. (1978). A First Course in Numerical Analysis (2nd ed.). New York: McGraw-Hill.

Raymer, D. P. (1999). Aircraft design: A conceptual approach (3rd ed.). Reston, VA: American Institute for Aeronautics and Astronautics.

Raymer, D. P. (2004). Approximate method of deriving loiter time from range. Journal of Aircraft, 41(4), 938-940. http://dx.doi.org/10.2514/1. 523

Rivas, D, \& Valenzuela, A. (2009). Compressibility effects on maximum range cruise at constant altitude. Journal of Guidance, Control, and Dynamics, 32, 1654-1658. http://dx.doi.org/10.2514/1.44039

Roskam, J, \& Lan, C. T. (1997). Airplane aerodynamics and performance, LawrenceKS: DAR Corporation.

Saarlas, M. (2007). Aircraft performance. Hoboken, NJ: John Wiley \& Sons.

Shevell, R. S. (1989). Fundamentals of flight, Englewood CliffsNJ: Prentice Hall.

Swatton, P. J. (2008). Aircraft performance: Theory and practice for pilots (2nd ed.). ChichesterUK: John Wiley \& Sons.

Thomas, A.. S. W. (1985). Aircraft viscous drag reduction technology. Lockheed Horizons, 19, 22-32.

Torenbeek, E. (1997). Cruise performance and range prediction reconsidered. Progress in Aerospace Sciences, 33, 285-321. http://dx.doi. org/10.1016/S0376-0421(96)00007-3

Torenbeek, E. (2013). Advanced aircraft design: Conceptual design, technology and optimization of subsonic civil airplanes. ChichesterUK: John Wiley \& Sons. http://dx.doi.org/10.1002/9781118568101

Torenbeek, E, \& Wittenberg, H. (2009). Flight physics. Amsterdam: Springer. http://dx.doi.org/10.1007/978-1-4020-8664-9

Treager, I. E. (1996). Aircraft gas turbine engine technology (3rd ed.). New York: Glencoe, McGraw-Hill.

Vallone, M. (2010). Parameter estimation of fundamental technical aircraft estimation applied to aircraft performance (MS thesis). California Polytechnic State University, San Luis Obispo.

Vinh, N. X. (1993). Flight mechanics of high-performance aircraft. Cambridge: Cambridge University Press.

Walsh, P. P, \& Fletcher, P. (1998). Gas turbine performance. London: Blackwell Science. 